\title{
The Role of Biomarkers in Cardio-Oncology
}

\author{
Kajaluxy Ananthan ${ }^{1}$ (D) Alexander R. Lyon ${ }^{1,2}$
}

Received: 29 January 2020 / Accepted: 26 May 2020 / Published online: 8 July 2020

(C) The Author(s) 2020

\begin{abstract}
In the field of cardio-oncology, it is well recognised that despite the benefits of chemotherapy in treating and possibly curing cancer, it can cause catastrophic damage to bystander tissues resulting in a range of potentially of life-threatening cardiovascular toxicities, and leading to a number of damaging side effects including heart failure and myocardial infarction. Cardiotoxicity is responsible for significant morbidity and mortality in the long-term in oncology patients, specifically due to left ventricular dysfunction. There is increasing emphasis on the early use of biomarkers in order to detect the cardiotoxicity at a stage before it becomes irreversible. The most important markers of cardiac injury are cardiac troponin and natriuretic peptides, whilst markers of inflammation such as interleukin-6, C-reactive protein, myeloperoxidase, Galectin-3, growth differentiation factor-15 are under investigation for their use in detecting cardiotoxicity early. In addition, microRNAs, genome-wide association studies and proteomics are being studied as novel markers of cardiovascular injury or inflammation. The aim of this literature review is to discuss the evidence base behind the use of these biomarkers for the detection of cardiotoxicity.
\end{abstract}

Keywords Biomarker $\cdot$ BNP $\cdot$ Brain natriuretic peptide $\cdot$ Cardio-Oncology $\cdot$ Cardiotoxicity $\cdot$ Heart failure $\cdot$ Troponin

\section{Introduction}

There is an increasing interest in the use of cardiac biomarkers to guide the management of oncology patients receiving cardiotoxic cancer therapies. Biomarkers offer value to detect early cardiac injury or strain, often preclinical, confirm LV injury and/or dysfunction when imaging provides borderline or inconclusive information, guide treatment strategies including initiation of cardioprotection during ongoing cancer treatment to allow completion of cancer treatment safely and at follow-up to identify patients prior to the development of symptomatic heart failure (HF).

Cardiac biomarkers are generally circulating proteins or molecules which can be detected from blood samples and are markers of cardiotoxicity [1]. In cardio-oncology, cardiac

Associate Editor Ana Barac oversaw the review of this article

Alexander R. Lyon

a.lyon@imperial.ac.uk

1 Cardio-Oncology Service, Royal Brompton Hospital, Sydney St, Chelsea, London SW3 6NP, UK

2 National Heart and Lung Institute, Imperial College London, London, UK biomarkers provide a way to detect toxicity early, ideally prior to the development of irreversible organ damage, and if elevated, lead to a pathway of care which allows cancer patients to continue their treatment safely. Cardiac biomarkers may be applied at various stages of cancer management, i.e. calculation of baseline risk prior to starting cancer treatment to guide primary prevention treatment, during treatment in monitoring for early toxicity and screening for late side effects in survivors. In the future, there is the potential for using biomarker expression profiles to guide specific choices regarding cardiovascular preventative therapy. The aim of this review is to describe the current role of cardiac biomarkers in oncology patients, in respect of diagnosis, screening and surveillance for the development of cardiotoxicity, both during and after cancer treatment.

\section{What Is Cardiovascular Toxicity?}

The European Society of Cardiology (ESC) [2] in its consensus statement defines cardiovascular $(\mathrm{CV})$ toxicity as 'any heart injury (functional or structural) related to cancer treatment, taking into consideration chemotherapy, radiotherapy and cancer itself'. CV toxicity can be acute, subacute or delayed presenting many years after chemotherapy or radiotherapy, involving a range of cardiac structures leading to $\mathrm{HF}$, 
coronary artery disease, valvular heart disease, arrhythmias including cardiac conduction disease and pericardial disease.

Left ventricular injury, dysfunction and/ or HF are the most common cardiotoxicities stemming from cancer therapies. Definition in trials and routine clinical practice vary, which can lead to confusion in management, and currently the role of cardiac biomarkers needs clarification. The ESC Guidelines for the diagnosis and management of HF published in 2016 require an elevated natriuretic peptide level in the diagnosis of HF, but then, defined HF based upon left ventricular ejection fraction (LVEF) into preserved ejection fraction $(\mathrm{EF})>50 \%$, mid-range EF $(40-49 \%)$ and reduced EF $(<40 \%)$ [3]. Therefore, the presence of HF does not depend upon a specific LVEF threshold or value, as LVEF guides treatment options but not the diagnosis. In contrast, clinical oncology trials use the definition of HF as defined by the Common Terminology Criteria for Adverse Events (CTCAE) [4] and the ESMO Practice Guidelines [5], both of which require a change in $\mathrm{LVEF}$, i.e. a decrease of $\mathrm{EF}$ by $5 \%$ or more to less than $55 \%$ in the presence of symptoms of $\mathrm{HF}$ or an asymptomatic decrease in $\mathrm{EF}$ by $10 \%$ or more to less than $55 \%$.

LV dysfunction or HF is a well-recognised complication of anthracyclines and several targeted chemotherapies (Table 1). There is a growing rationale to detect LV dysfunction early, to treat and prevent the development of HF, as well as monitor its progression. Biomarkers are one technology to detect cardiotoxicity early before changes in LVEF, or clinical signs and symptoms of HF have developed. It is important to highlight that biomarkers should not be used in isolation, but rather placed in a comprehensive assessment including determination of cardiac function using imaging, risk factors, clinical symptoms and the context of the cancer (specifically whether it is localised versus metastatic disease and cancer prognosis).

Cardiotoxicity surveillance involving the detection of cardiac biomarkers combined with serial imaging may provide the most sensitive strategy to detect early toxicity and guide cardioprotective interventions [8]. Using this combined approach in a cardio-oncology service, cardiologists could

Table 1 A comparison amongst the different anthracyclines in terms of relative cardiotoxicity as defined by a decline in left ventricular function and bioequivalent doses $[2,6,7]$

\begin{tabular}{ll}
\hline Drug & Relative cardiotoxicity \\
\hline Doxorubicin rapid infusion & 1 \\
Epirubicin & 0.8 \\
Daunorubicin & 0.6 \\
Idarubicin & 0.53 \\
Liposomal anthracyclines & 0.5 (for doxorubicin) \\
\hline
\end{tabular}

support ongoing oncology treatment to completion in $88 \%$ of patients referred with cardiotoxicity from their current cancer treatment [9]. For example in a study by Pareek et al. [9], which explored the running of a cardio-oncology service over 5 years, it effectively demonstrated the importance of collaboration between cardiologists and oncologists in order to improve patient outcomes. Another challenge is the role in longterm surveillance for the development of late cardiotoxicity, which is more relevant at present with the increasing cancer survivorship seen. Critical questions include which cancer survivor patient cohorts should be screened, when should screening start, how long patients should be screened for and what biomarkers should be used to detect toxicity from specific oncology treatment regimens.

\section{Mechanisms of Toxicity}

Understanding the pathophysiology of cardiotoxicity is important to guide the selection of appropriate biomarkers for diagnosis and surveillance. Treatments first recognised to cause cardiovascular toxicity were anthracyclines and radiation therapy $[10,11]$. Specifically, left ventricular dysfunction is primarily due to anthracycline toxicity, whereas valvular dysfunction and coronary artery disease is due to radiation toxicity [11]. Several targeted cancer therapies cause LV dysfunction and HF including HER2 inhibitors (trastuzumab) [12], RAF-MEK inhibitors [13] and the EGFR inhibitor osimertinib [14]. Other targeted cancer therapies such as vascular endothelial growth factor (VEGF) signalling inhibitors and multi-targeted tyrosine kinase inhibitors have showed a broader spectrum range of $\mathrm{CV}$ toxic effects including LV dysfunction but also vascular toxicity, QT prolongation and arrhythmia risk, and in some cases pulmonary hypertension $[10,15]$. Therefore, biomarkers for this wider range of CV side effects should be developed for a more comprehensive approach.

Anthracycline chemotherapy is a cytotoxic form of chemotherapy, which acts by binding to topoisomerase II and generates reactive oxygen species leading to cell death, which is a common cause of cardiotoxicity $[15,16]$. Anthracyclines includes doxorubicin, epirubicin, idarubicin and daunorubicin, and they are used to treat a wide range of cancers including breast cancer, lymphoma, acute leukaemia, sarcomas and a range of paediatric cancers. Approximately $10 \%$ of patients experience cardiotoxic side effects stemming from anthracyclines, with some detectable during treatment, others within the first 12 months following treatment and then late presenting cases up to 30 years later [17]. Anthracyclines can cause myocardial toxicity via oxidative stress, mitochondrial dysfunction, which may initially be reversible, before 
progressing to myocardial injury with apoptosis, necroptosis and cardiomyocyte cell death leading to a troponin leak [6]. Table 1 demonstrates the relative differences in cardiotoxicity amongst the different anthracycline class members.

Trastuzumab, the humanised monoclonal antibody generated against the HER2/neu receptor, also known as Herceptin ${ }^{\circledR}$, is known to cause left ventricular dysfunction, which in severe cases can lead to HF. However this HF syndrome is usually, but not always, reversible on cessation of trastuzumab treatment and initiation of HF medications $[15,18]$. The mechanisms of cardiotoxicity are complex, and one part is via inhibition of the beneficial and cardioprotective effects of neuregulin-1 signalling via the HER2 receptor in the heart (Fig. 1). Cardiac HER2 signalling is a protective pathway which is upregulated in the hearts under increased stress from pre-existent heart disease or recent trastuzumab treatment [19]. Neuregulin-1 normally acts on the heart via either ErbB4/ErbB4 receptor homodimers or ErbB4/ErbB2 heterodimers to promote protective pathways in the presence of cell stressors $[20,21]$. Trastuzumab causes functional abnormalities rather than myocyte necrosis or apoptosis, unless concomitantly delivered with other chemotherapeutic agents $[22,23]$. Hence, this suggests that it directly causes stress rather than myocyte injury, but in patients with actived anthracycline-initiated apoptosis, it may exacerbate the injury and myocyte cell death by inhibiting the antiapoptotic pathways. Other chemotherapeutic agents responsible for reversible cardiotoxicity include VEGF inhibitors [22].

VEGF inhibitors (VEGFi, e.g. pazopanib, sorafenib, sunitinib) [24] and BCR-ABL tyrosine kinase inhibitors [15] are examples of anti-cancer therapies which can cause both direct LV systolic dysfunction and indirect LV dysfunction via coronary artery disease including acute myocardial infarction and hypertension [25]. Other CV adverse effects include thrombotic events, QTc interval prolongation and HF [26-29].

Schutz et al. calculated that the relative risk of mortality was 2.23 (95\% CI, 1.12-4.44) in a meta-analysis of 4679 patients treated with sunitinib, sorafenib or pazopanib [30]. VEGF inhibitor-related CV toxicity is usually reversible when the VEGFi is stopped and with appropriate CV treatment [22]. The clinical challenge in these cases is that VEGFis are a key component of treatment of a range of metastatic cancers, and therefore efforts must be made to control the $\mathrm{CV}$ toxicity in order to continue treatment safely.

VEGF-related hypertension occurs via various mechanisms, including impaired endothelial function secondary to decreased nitric oxide availability, increased vascular tone and decreased microvascular density [31]. Renal dysfunction due to thrombotic microangiopathy is an important factor leading to hypertension especially with bevacizumab [32]. The development of hypertension with VEGFis is associated with improved survival in patients with metastatic renal cancer. Rini et al. [33] showed an improved survival of 30.9 months (95\% $\mathrm{CI}=27.9-33.7$ months) in patients who developed hypertension with bevacizumab compared with 7.2 months (95\% CI $=5.6-10.7$ months) in patients who did not. Therefore, although the development of hypertension is a complication, it is also a marker of efficacy.

Proposed mechanisms for the development of thrombotic events include disruption of endothelial cell integrity [27], platelet aggregation and degranulation [34], which are all considered reversible. However, thrombotic events and myocardial infarction lead to increased mortality which has been confirmed in various meta-analysis [35]. Despite all these potentially serious CV toxicities from VEGF inhibitors, it is important to remember that there is improved survival from cancer and overall survival on patients on VEGF inhibitors. The role of cardiac biomarkers in VEGF inhibitor-related CV toxicities is limited, and the only biomarkers currently available with growing evidence are natriuretic peptides (NPs). Nevertheless, it has been shown that asymptomatic cardiotoxicity is increasingly more common, but was only detected in 43 patients (27\%) by either an increase in NPs or a decline in LVEF [36]. Morever, there is no specific link between an elevation in specific biomarkers and the biological mechanisms behind causing cardiotoxicity. Biomarkers which could detect early LV dysfunction more specifically than NPs, identify VEGFi-related hypertension early on, or predict arterial thrombosis could lead to more specific treatments to prevent clinically significant $\mathrm{CV}$ toxicities and keep patients on their effective VEGFi for longer [33, 35, 37].

The immune checkpoint inhibitors (ICIs) are a new class of cancer therapies, which activate the immune system to target and destroy cancer cells. ICI target receptors and signalling pathways involved in immune escape of cancer cells include cytotoxic $\mathrm{T}$ lymphocyteassociated protein 4 receptor (CTLA4), programmed cell death protein-1 (PD-1) and programmed cell death protein ligand-1 (PD-L1) [38]. Despite being shown to enhance clinical outcomes in cancer patients, ICIs can also cause a range of cardiovascular toxicities [39]. Most of the $\mathrm{CV}$ toxicities from ICI treatments are immune-mediated, and the most common and most serious is autoimmune T-lymphocytic myocarditis. In addition, ICIs can cause complete heart block, acute coronary syndromes secondary to both atherosclerotic plaque rupture and autoimmune vasculitis, pericarditis and a new emerging syndrome of non-inflammatory left ventricular dysfunction [38]. More studies are required to phenotype the spectrum of ICI-mediated $\mathrm{CV}$ toxicities and the role of biomarkers in diagnosis, surveillance and monitoring response to treatment agents [40]. 
Chimeric antigen receptor therapy (CAR-T therapy) is a novel form of immune therapy where $\mathrm{T}$ cells are genetically engineered to target tumour cells. CAR-T cell therapy is used in the treatment of various haematological and solid cancers; the main side effect is a cytokine release storm (CRS) leading to a systemic inflammatory response syndrome with multiorgan failure including cardiotoxicity. There is also an increased risk of arrhythmias, namely SVT and atrial fibrillation [41]. A study assessing cardiovascular complications in 93 children treated with CAR-T therapy for leukaemia reported that there were 21 cases of hypotension requiring inotropic support with onset at a mean of 4.6 days [42]. In this group, $41 \%$ had systolic dysfunction on echocardiogram, whilst $7 \%$ had new cardiac dysfunction maintained until discharge, this was persistent at 6 months in 1 patient only [42]. In a recent report of 137 adult cancer patients receiving CAR-T, the evidence of new $\mathrm{CV}$ events occurred in $31 \%$ of the patients with grade $\geq 2$ CRS including decompensated HF, arrhythmias and $\mathrm{CV}$ death [43].

\section{Current Methodology for Diagnosis of Cardiotoxicity}

The American Society of Echocardiography and the European Association of Cardiovascular Imaging have defined one feature of cardiotoxicity as the reduction in LVEF $>10 \%$ resulting in a value $<53 \%$ (normal limit if 2-Dimensional echocardiography is used) [44]. The European Society of Cardiology 2016 have stated that echocardiography (3Dimensional if endocardial border is clear or 2-Dimensional with biplane Simpson method) is the most optimal choice for detecting cardiotoxicity leading to left ventricular dysfunction at all stages of chemotherapy, with cardiotoxicity defined as a decrease in LVEF > $10 \%$ to reach a value below the normal limit for ejection fraction [2]. The frequency of assessment needed to detect cardiotoxicity is determined by the underlying cancer treated, the cardiotoxic cancer therapy and planned duration, type, total dose and baseline cardiovascular risk in all haematology and oncology patients. It is increasingly recognised that diagnosing cardiotoxicity based on symptoms alone or waiting for a decline in ejection fraction which causes symptoms is too late, and it means that the degree of myocyte damage is no longer reversible. Also, this method does not detect cardiotoxicity manifesting structurally such as myocarditis.

A prospective study [17] involving a large cohort of patient showed that regular echocardiography allowed identification of cardiotoxicity in $98 \%$ of patients in the first year of treatment, such that with treatment using ACE inhibitors and beta blockers, $82 \%$ of patients were able to recover on follow-up and achieve a normal EF. However, in $71 \%$ patients, the EF achieved with this medical treatment was below their value prior to chemotherapy. This emphasises the importance of earlier detection of cardiotoxicity before a decline in EF, which paves the importance of biomarkers as a tool for early detection of cardiotoxicity in current cardio-oncology practice.

\section{Cardiac Troponin}

Cardiac troponins (cTn) (both troponin I and troponin $\mathrm{T}$ ) are the gold standard biomarkers for the detection of cardiac injury and cardiomyocyte necrosis, and the most extensively used biomarker to detect cardiac toxicity $[45,46]$. They have high specificity for cardiac injury, but also with the advent of high sensitive assays means that it is possible to detect small amounts of myocyte damage and help provide treatments to minimise cardiotoxicity prior to the development of irreversible LV dysfunction [47]. The importance of monitoring troponin to detect cardiotoxicity has been demonstrated mainly from studies of cancer patients receiving chemotherapy, mainly anthracycline [48]. A persistent elevation of troponin I is associated with a greater degree of LV dysfunction and a higher incidence of cardiac events compared with transient elevations in the troponin levels [47]. Troponin $\mathrm{T}$ is generally considered less useful as a marker as studies have shown that it is not associated with myocardial infarction or coronary heart disease, but instead is more closely linked to the risk of death which is not directly attributed to cardovascular disease [49].

\section{Anthracyclines}

The importance of troponin as a marker of anthracycline-induced cardiotoxicity was first demonstrated in animal models. Clinical studies in both children and adults have shown that elevated troponin levels during chemotherapy is an early marker of increased risk of left ventricular dysfunction [46-48, 50-67]. The largest study to date involved 703 patients with cancer where troponin I was measured using a conventional assay (defined as an assay cut-off of above $80 \mathrm{ng} / \mathrm{L}$ representing a significance elevation in troponin I) before chemotherapy, within 3 days of commencing chemotherapy and after 1 month [47]. Troponin I was in the normal range in $70 \%$ (495 patients), and in the remaining 208 patients increased at 3 days only in 145 patients and increased in both early and late stages in 63 patients. Patients without troponin I elevations had no significant reduction in LV function and had a good prognosis with an incidence of $1 \%$ of cardiac events at 3-year follow-up. On the other hand, elevation of 
troponin I was associated with a higher incidence of adverse cardiovascular events. Specifically, the maintenance of troponin I elevation after 1 month was associated with greater LV impairment and higher incidence of cardiovascular events compared with an isolated elevation of troponin I at only 3 days $(84 \%$ vs $37 \% ; p<$ 0.001 ) [47]. Similarly, the incidence of adverse events was greater in the group who had a persistent rise in the troponin levels during anthracycline chemotherapy.

Another study involving 204 patients with malignancies requiring anthracyclines involved measuring troponin for every cycle of high-dose chemotherapy [46]. In total 65 patients $32 \%$ had elevated troponin $(>50 \mathrm{ng} / \mathrm{L})$. This was linked to a greater reduction in LVEF on long-term follow-up such that when LVEF $<30 \%, 100 \%$ of patients had troponin $>50 \mathrm{ng} / \mathrm{L}$ and the higher the troponin the greater the reduction in LVEF. Both studies, hence, validate the importance of using conventional troponin for surveillance post-chemotherapy as both a sensitive and reproducible marker of myocardial dysfunction, prior to development of HF. There is also increasing data emerging from survivors of childhood cancers which shows that cTnI and hs-TnI were not consistently elevated in patients who developed LV dysfunction on imaging [68-70]. Hence, these studies demonstrate that although troponin is a sensitive marker during and early after chemotherapy, it is not a sensitive marker for ongoing surveillance of subclinical cardiotoxicity post-chemotherapy, when compared to other biomarkers such as NPs.

\section{Trastuzumab}

Troponin I has a negative predictive value of $99 \%$ which helps reliably identify patients who do not need regular follow-up [47]. The role of troponin as a marker of cardiotoxicity with other cancer therapy regimens apart from the anthracyclines is still under research [48, 50, $52,56,57,59]$. In breast cancer patients treated with trastuzumab, 16 patients who developed LV dysfunction did not demonstrate an increase in troponin [48]. LV dysfunction quickly recovered on cessation of treatment, hence this could represent myocardial sensence induced by trastuzumab instead of myocaridal toxicity. This same study involving 251 trastuzumab-treated patients showed than an increase in troponin in 36 patients $(14 \%)$ predicted LV dysfunction and poor prognosis, and hence demonstrates its specificity for use in clinical practice [48].

The largest study of cardiac troponin is the HERA trial cardiac biomarker substudy of 533 women receiving trastuzumab for HER2+ breast cancer [71]. They reported an elevated cardiac troponin post-anthracycline treatment but before trastuzumab (baseline pre trastuzumab) and that this baseline troponin predicted which women developed future trastuzumab-induced cardiotoxicity as signified by a decline in LVEF (hazard ratio 3.57-4.52 vs no troponin rise), whereas troponin surveillance during trastuzumab was not sensitive. In line with the HERA trial substudy, several other studies also reported that surveillance with cardiac troponin during trastuzumab treatment did not predict LV dysfunction [72-74]. This could be related to the different preceding chemotherapy regimens (anthracyclines vs non-anthracyclines), the variation in the sampling time, the different troponin assays used and the length of follow-up [51]. For example, it has been shown that exposure to doxorubicin in childhood can lead to increased risk of morbidity and mortality $[75,76]$ of up to 3.1-fold in 30-year-old survivors [77].

\section{Immunotherapy}

Cancer treatment has greatly advanced with the widespread use of immune checkpoint inhibitors [78]. Nevertheless, their increasing use is not without problems, specifically immune checkpoint inhibitor (ICI)-mediated myocarditis [79-82]. ICI-mediated myocarditis can be detected through an increase in serum troponin, which is one of the main diagnostic criteria for diagnosis in general cardiology. However, in one of the larger published cohorts of ICI myocarditis, only $94 \%$ of patients had an elevated troponin at presentation [79]. Therefore, $6 \%$ of the cases in this cohort had ICI-mediated myocarditis diagnosed clinically with normal cardiac troponin levels. This, therefore, demonstrates that biopsy-proven, troponin-negative ICI-mediated myocarditis can occur. The paper from Mahmood et al. [79] also highlighted the increased mortality if patients are discharged from hospital with myocarditis still active and not fully suppressed. In this cohort, the patients with cardiac troponin at discharge that was greater than $1.5 \mathrm{ng} / \mathrm{mL}$ had a fourfold higher risk major adverse cardiac events (MACE) at follow-up. Therefore in addition to diagnosis, serial troponin measurements are required to monitor response to immunosuppressant treatment and timing of when patients with ICI myocarditis are safe to discharge home on oral steroid therapy. A recent paper defined the criteria for ICIrelated myocarditis [80]. The role of troponin surveillance has been proposed and requires prospective research studies for validation, at least for patients considered at higher risk of myocarditis and CV complications [80, 81]. If applied, it is recommended that troponin measurements at baseline and weekly during cycles $1-3$ can detect this myocarditis-related toxicity early [82].

\section{CAR-T Cell Therapies}

The study of 137 adult cancer patients receiving CAR-T reported that cardiac troponin was a sensitive biomarker for the detection of $\mathrm{CV}$ toxicities [43]. Cardiac troponin was found to be elevated in 29 of 53 tested patients (54\%) and was elevated in $95 \%$ of patients who subsequently developed clinical CV 
toxicity. Therefore, it appears that an inflammatory CAR-Tmediated myocarditis may occur in some patients as part of their cytokine release storm [83], and occurs early (with a median of 5 days after treatment) [43]. Hence, a short period of cardiac troponin surveillance may be warranted and should be studied prospectively in larger cohorts.

\section{Natriuretic Peptides}

Two NPs, i.e. brain natriuretic peptide (BNP) and N-terminal pro-B type natriuretic peptide (NT-proBNP) $[8,52$, 84-86] are simulated to be secreted by cardiomyocytes from increased transmural tension and neurohormonal stimulation (notably by noradrenaline and angiotensin II). BNP is derived from cleavage of pre-proBNP leading to BNP and the biologically inactive N-terminal containing fragment (NTproBNP). NT-proBNP has also been used in it own right as a biomarker for detection of HF [87, 88]. Hence, NPs are important biomarker of pressure overload and myocardial stretch $[89,90]$ and, their ability to detect haemodynamic stress makes them an important maker of cardiotoxicity, as well as for long-term surveillance in the management of heart failure. NPs may also be used to detect acute cardiotoxicity as levels increase within $24 \mathrm{~h}$ of exposure to anthracycline chemotherapy [91, 92]. NPs are also an important screening tool for HF in patients presenting with dyspnoea on cancer therapy, but it has been shown that a cut-off value of $100 \mathrm{ng} / \mathrm{L}$ for NT-proBNP has a high sensitivity (0.92), but low specificity (0.5) for cardiotoxicity as there are other causes of increased NPs including, for example atrial fibrillation and valvular heart disease [93].

Several studies have analysed the role of NPs in various oncology populations. One study measured NP in an unselected cohort of 600 successive newly diagnosed cancer patients to their large oncology service. An elevated baseline NTproBNP pre-oncology treatment was a signifcant predictor of mortality risk: hazard ratio 1.54 (95\% CI 1.24 to 1.90 , $\mathrm{p}<0.001)$ with a Kaplan-Meier survival rate of $67 \%$ versus $49 \%$ (in patients with normal NT-proBNP, $\mathrm{p}<0.001$ ) at a median of 25 months follow-up [94].

Most studies of NPs have been in patients receiving anthracyclines or anthracyclines and trastuzumab; treatments which both cause LV dysfunction and HF. One study evaluating NT-proBNP in 52 patients treated with high-dose anthracyclines with normal NT-proBNP at baseline, three different patterns of elevation of proBNP have been identified [95]: 17 patients had elevated NT-proBNP immediately after starting treatment which remained elevated at 72 hours $[160(95) \mathrm{ng} / \mathrm{L}$ at baseline; 1163 (936) ng/L after $72 \mathrm{~h}$; $\mathrm{P}<0.00038]$, in 19 patients NT-proBNP only increased after 12-36 hours after treatment and decreased back to baseline after 72 hours $[120$ (107) ng/L at baseline; 185 (101) ng/L after $72 \mathrm{~h} ; \mathrm{P}=0.002]$, and in the final group NT-proBNP decreased from baseline after 72 hours $[90(95) \mathrm{ng} / \mathrm{L}$ at baseline; 39 (19) $\mathrm{ng} / \mathrm{L}$ after $72 \mathrm{~h}$; $\mathrm{P}=0.04]$. In patients with high NT-proBNP at 1-year follow-up, there was a significant reduction in LVEF, and there was a strong correlation between the level of NT-proBNP at $72 \mathrm{~h}$ and the degree of reduction of EF at 12-month follow-up as well as other markers of systolic and diastolic dysfunction including: change in ratio of peak early to peak late flow velocities ( E/A) from $>1$ to $<1$, E-wave deceleration time and isolvolumetric relaxation time. Therefore, measurement of NPs not only helps identify patients who will develop cardiotoxicity, but may also help determine the degree of cardiac dysfunction.

Similar evidence also exists for BNPs as a marker of cardiotoxicty. A single-centre study of 109 cancer patients undergoing treatment with anthracyclines showed that $10.1 \%$ of patients experienced a cardiac event (namely LV dysfunction, symptomatic HF, arrhythmia, sudden cardiac death or ACS), and all of these patients had a BNP $>100 \mathrm{ng} / \mathrm{L}$ prior to the event [92]. This supports the strategy of regular BNP measurements as well as imaging to detect cardiotoxicity. However this study highlighted that not all these patients ended up developing LV dysfunction. On the other hand another study involving children treated with doxorubicin, BNP elevation was predictive of development of cardiomyopathy as signified by LV dysfunction $(p<0.01)$ when compared to healthy patients as the control [96]. Similarly, in the HERA breast cancer trial of trastuzumab, the cardiac biomarker substudy reported that new rises in NT-proBNP during trastuzumab treatment were most predictive of a subsequent reduction in LV function on echocardiographic surveillance, although it was a trend which did not reach statistical significance [71]. However there remains disparity with the results, for example another study involving 43 patients with left-sided breast cancer after radiotherapy, serial BNP measurements up to 12 months post-therapy showed that small BNP elevations were predictive for the development of radiotherapy-related cardiovascular events, although none of the patients developed evidence of LV dysfunction [97].

In patients receiving ICIs, the main application of NPs was in the diagnosis of new LV dysfunction. This can be in the context of ICI-mediated myocarditis [79], although NPs are raised in only two-thirds of cases with myocarditis. The main role of NPs in our clinical practice is to diagnose non-inflammatory $\mathrm{LV}$, 
dysfunction as this new and emerging clinical entity can be partly differentiated by the rise of NPs with a normal serial cardiac troponin levels, ideally measured with a high sensitive assay. The diagnosis also requires clinical and imaging evidence of new LV dysfunction and absence of myocardial inflammation on cardiac imaging and/ or endomyocardial biopsy.

Proteasome inhibitors (PIs) are an effective treatment of multiple myeloma (MM), and 3 are currently licensed (bortezomib, carfilzomib and ixazomib). PIs have various cardiovascular toxicities, and in particular, the most potent PI carfilzomib can cause HF, acute coronary syndromes, arrhythmias and sudden death. Cornell and colleagues [98] reported the CV complications in 95 adult MM patients treated with carfilzomib $(n=65)$ or bortezomib $(n=30)$. Clinical CV complications, called $\mathrm{CV}$ adverse events (CVAEs), was $50 \%$ in carfilzomibtreated and $17 \%$ in bortezomib-treated MM patients, including HF, ACS, arrhythmia, pulmonary arterial hypertension, hypertension and venous thromboembolism. Elevated baseline NPs before treatment was associated with a 10.8-fold increased risk of a CVAE compared with MM patients with a normal baseline NPs. A new rise in NPs in the carfilzomib-treated patients during treatment occurred predominantly in the first 6 months of treatment, but specifically it has been shown that the early rise taking within the first 3 weeks of carfilzomib treatment was associated with a 36-fold increased risk of CVAEs ( $95 \%$ CI, 4.4 to $296 ; p<0.001$ vs no rise). CVAEs were associated with interruption of PI and worse overall survival (median 18.1 months for patients with CVAE vs not reached in the MM patients without a CVAE), with $88 \%$ of deaths due to MM disease progression. Therefore, measurement of NPs at baseline and early during treatment may help identify higher risk patients for closer surveillance and implementation of cardioprotective treatments and intense control of $\mathrm{CV}$ risk factors.

Limitations in all the studies assessing the role of NPs in cancer patients are small study sizes, retrospective design and lack of reference ranges, cohorts are small and unmatched cohorts between different studies, different cancer types with different chemotherapy regimens, limited follow-up, variable defined endpoints, variable cut-off values for BNP and timepoints when the BNP was measured. It is also recognised that in elderly patients and females, high levels of NPs can be normal [99, 100]. Similarly, renal dysfunction can also increase levels of NPs [101], whereas obesity is associated with lower levels of NPs. Finally, inflammation secondary to cancer has also been shown in some studies to cause elevation of NPs [102].

\section{Do Troponin and Natriuretic Peptides Convey Different Information?}

Troponin as a biomarker defines cardiomyocyte injury [65, $103,104]$ (Table 2), whereas BNP is a marker of increased myocardial strain (Table 3) $[65,90]$. NPs are excellent markers of long-term cardiovascular dysfunction in asymptomatic patients [138]. Other biomarkers provide information on acute injury but may not remain elevated in the long-term.

\section{Role of Biomarkers to Detect Shared Risk Factors for Heart Failure or Cancer}

Evidence is emerging about a common underlying pathophysiology between cardiovascular disease and cancer [107]. Inflammation is a common mediator of both processes, and hyperglycaemia, hyperinsulinaemia and IGF1 are also important [108]. In this way, markers of inflammation are increasingly recognised as important in detection of cardiotoxicity.

\section{Inflammatory Mediators}

Interleukin-6 has been shown to be associated with increased risk of cardiovascular events (MACE, MI and cardiovascular death) as well as all-cause mortality and increased risk of cancer [109]. IL-6 is considered an important inflammatory marker important in the process of atherosclerosis. Its effects are mediated by downstream inflammatory proteins, namely $\mathrm{C}$-reactive protein (CRP) [110].

CRP is an acute phase reactant produced by hepatocytes due to simulation by interleukin- 6 produced by macrophages and $\mathrm{T}$ cells [110]. Elevated hsCRP is associated with decreased LVEF in patients with varying cardiovascular disease ranging from myocardial infarction and HF [110]. A study involving 54 women treated with trastuzumab showed that hsCRP $>3 \mathrm{mg} / \mathrm{L}$ was 92.9\% sensitive and $45.7 \%$ specific for LVEF reduction which is clinically significant [111]. Peak levels of hsCRP were detected after a median of 78 days before cardiotoxicity became evident as quantified by a decrease in LVEF. However, other studies failed to show a conclusive link between elevated CRP and cardiotoxicity [8, 139]. A specific use of CRP may lie with $\mathrm{T}$ cell therapies, namely Chimeric Antigen Receptor (CAR) $\mathrm{T}$ cells where daily measurements of CRP is essential to detect cytokine release storm, which may present as severe hypotension, LV dysfunction, arrhythmia and cardiac arrest $[56,112]$. Nevertheless, the limitation of hsCRP is that is has a low specificity 


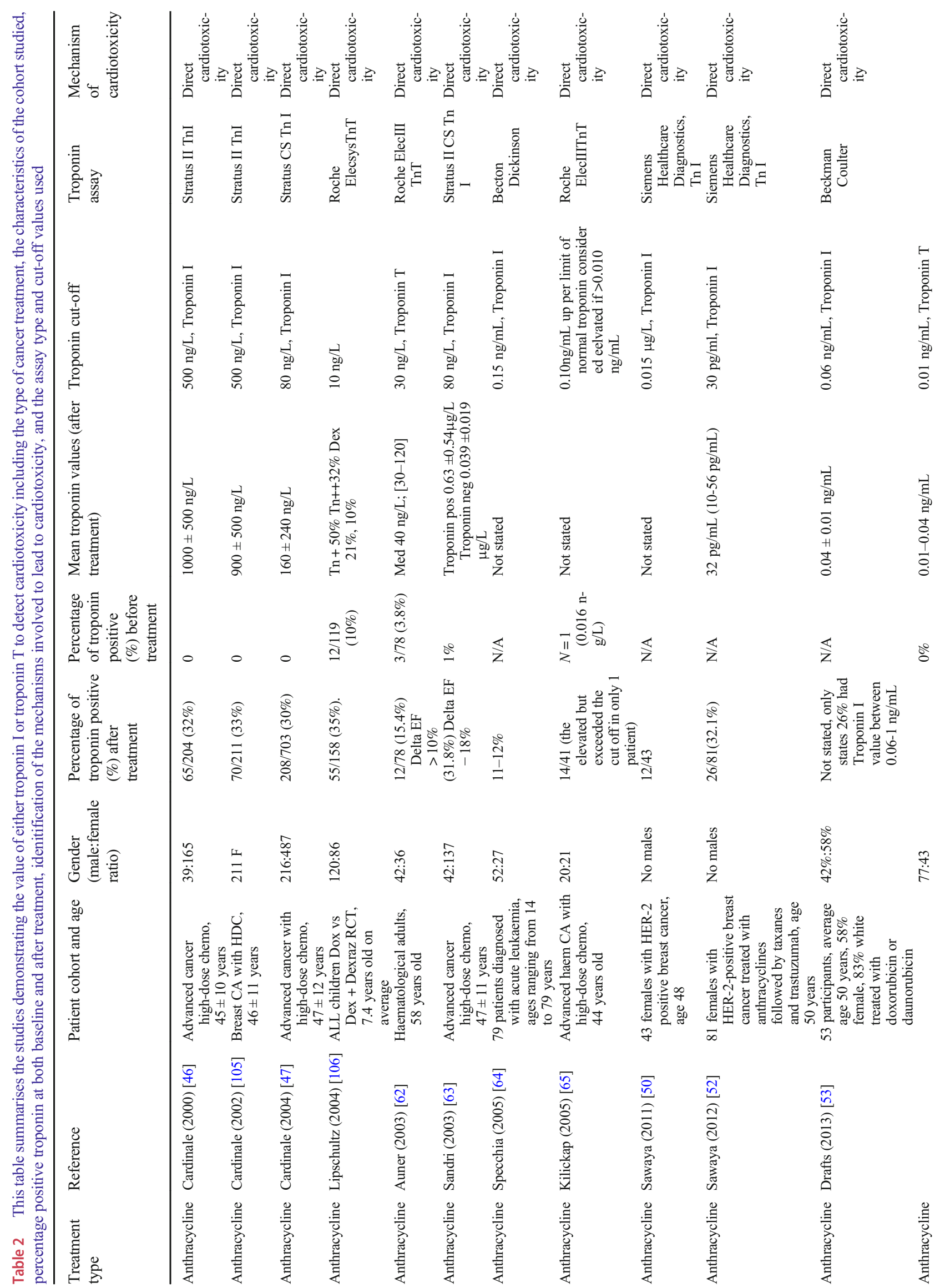




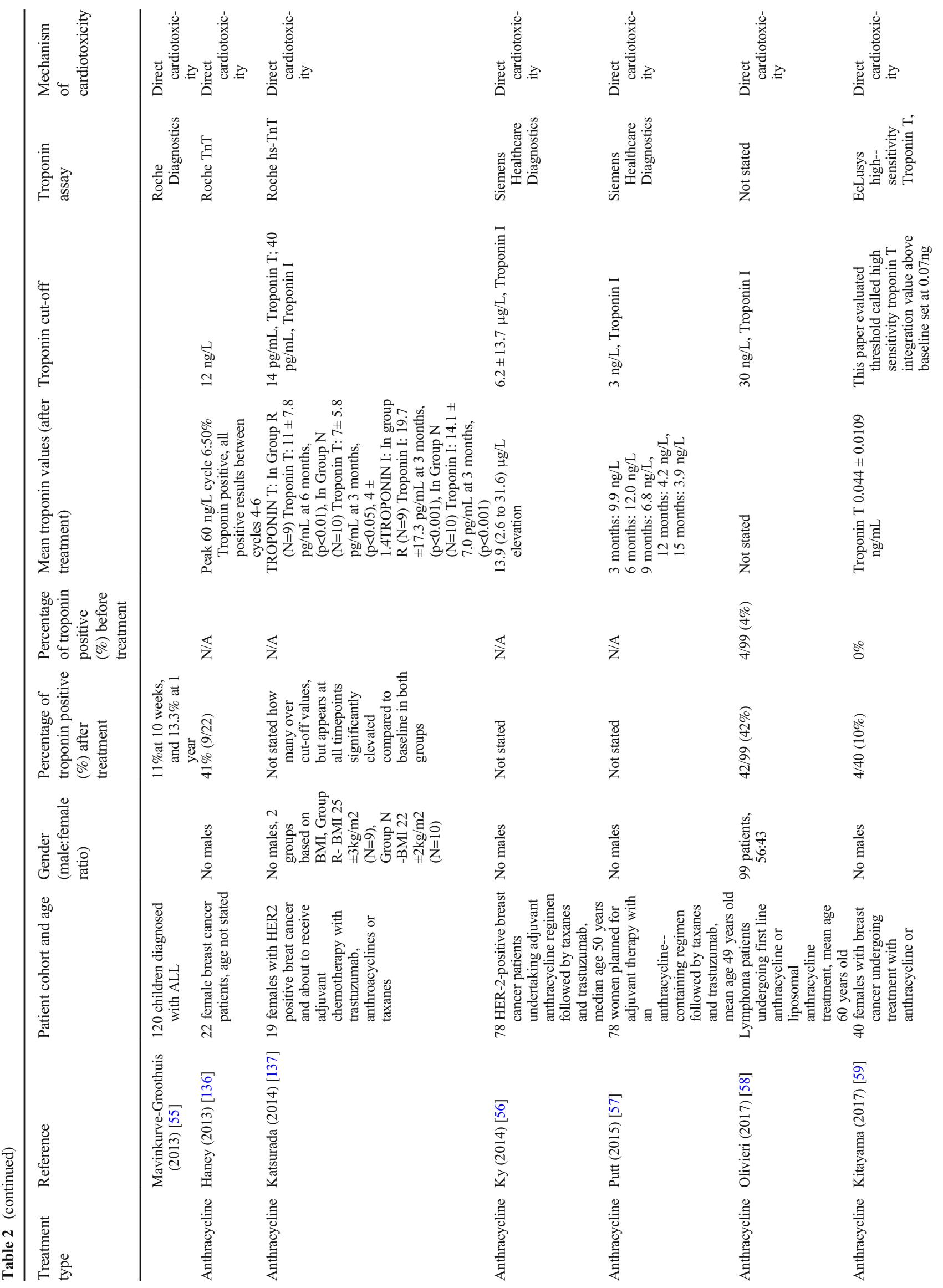




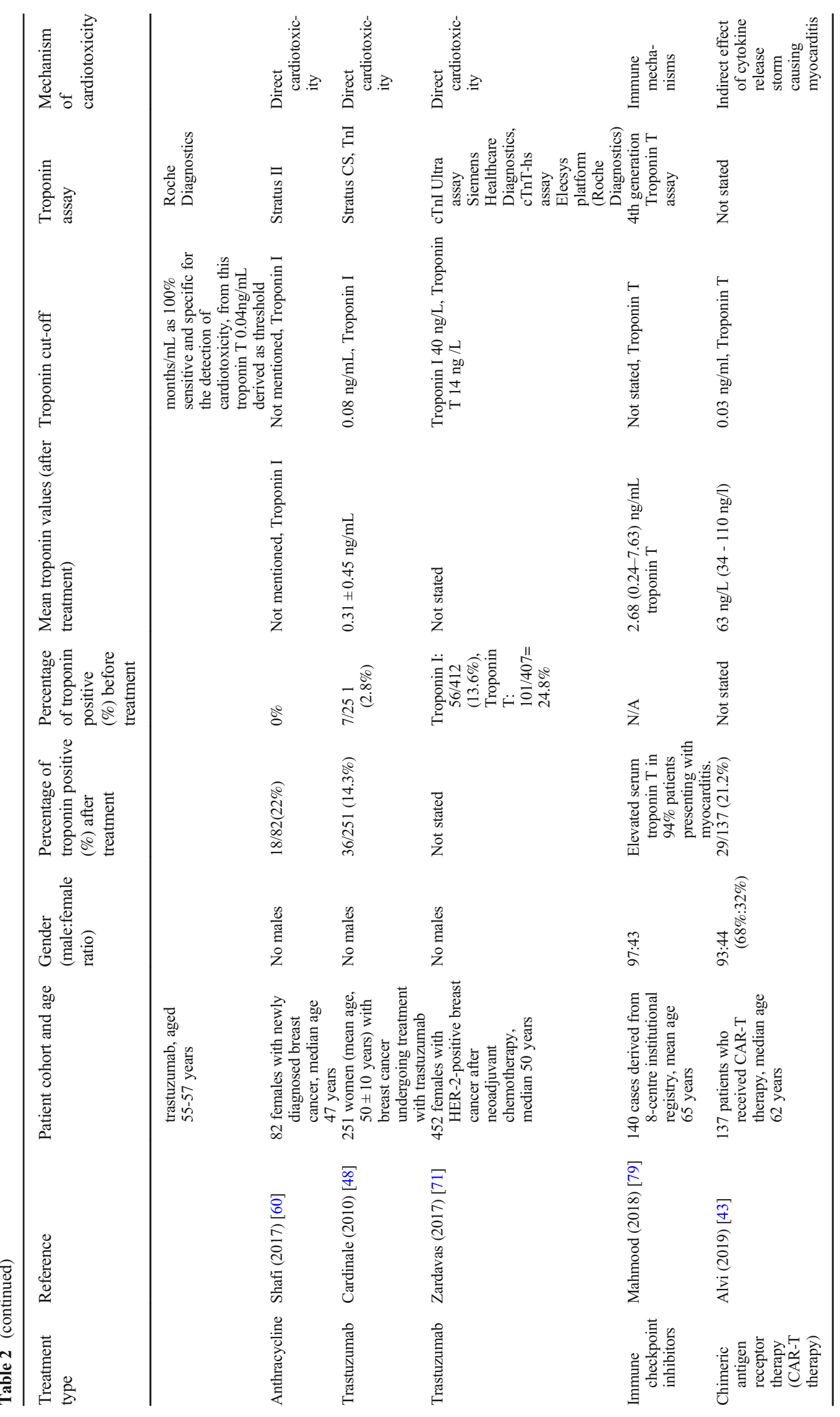




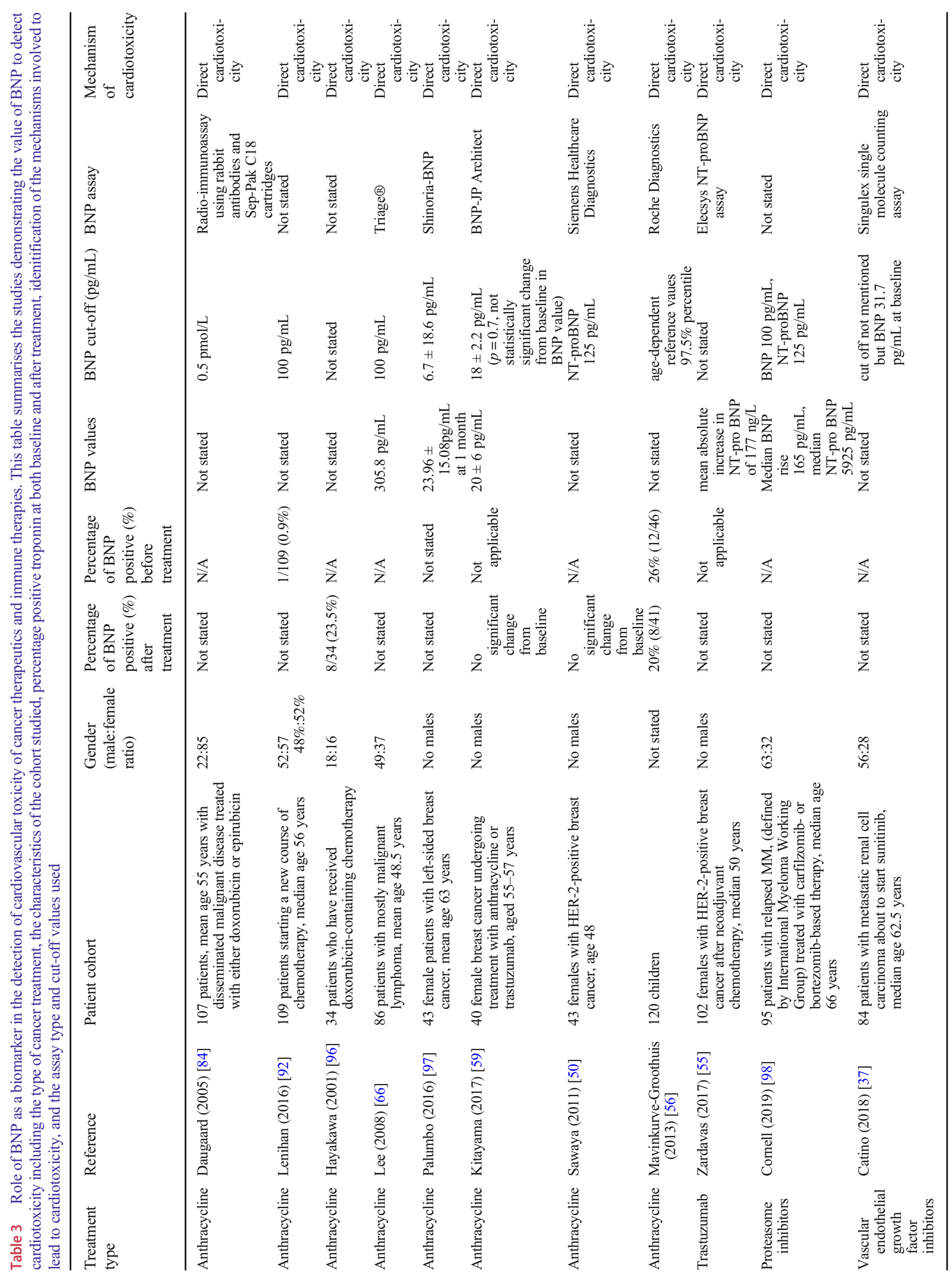


when elevated of $45.7 \%$ and a positive predictive value for the detection of a decline in LVEF of $40.6 \%$. Hence due to the risks of achieving false positive values, a high level does not confirm developement of LV dysfunction [111].

There is increased recognition of the overlap between innate immune and inflammatory pathways which are key in cardiac remodelling $[113,114]$. The central mediators are expressed in both cardiomyocytes and fibroblasts. When the adaptive immune system is activated, the activation of antigen presenting cells by $T$ cells is key to healing after a myocardial infarction and cardiac remodelling pathways $[115,116]$. This immunological, pro-inflammatory response which in turn is important in the pathophysiology of HF also has an impact on the physiology of distant organs including tumours [117].

\section{Novel Cardio-Oncology Biomarkers Under Investigation}

\section{Myeloperoxidase}

Myeloperoxidase (MPO) (produced and secreted by leukocytes) has atherogenic and pro-oxidant effects on cardiac tissue leading to its association with increased risk of coronary artery disease and acute $\operatorname{HF}[118,119]$. MPO is an enzyme produced by polymorphonuclear leukocytes [120], which is pro-atherogenic and pro-oxidant, being responsible for lipid peroxidation, NO scavenging and NO synthase inhibition [121]. In patients in ACS, elevated MPO levels despite normal troponin T levels is important in predicting adverse outcomes [118]. MPO may also be predictive of worse prognosis in acute HF patients [119] and MPO-mediated cardiotoxicityis most likely linked to oxidative stress [122]. MPO has been shown to work synergistically with troponin to predict adverse cardiovascular outcomes. The first description of the link between increase in MPO levels and the development of cardiotoxicity was described following treatment with doxorubicin and trastuzumab [56]. MPO elevation was clinically significant even at baseline (a characteristic unique to this biomarker $(p=0.052))$ and also clinically significant in terms of the absolute difference in its levels between the second cycle compared to at baseline (HR 1.34; 95\%CI, $1-1.8 ; p=0.048)$ [56].

\section{Markers of Extracellular Matrix Turnover and Fibrosis}

Galectin-3 could be an important biomarker which plays an important role in remodelling and development of cardiac fibrosis [56, 123]. Galectin-3 is a $26-\mathrm{kDa}$ protein produced by macrophages and stimulates pro-fibrotic pathways leading to fibroblast proliferation and hence collagen deposition. In patients with either acute or chronic decompensated HF, studies have shown Galectin-3 levels are important in predicting mortality rates $[124,125]$. ST-2 is a receptor from the Interleukin-33 family and consists of 2 gene forms, i.e. soluble ST2 (sST2) and transmembrane ST2. Blood levels of ST-2 can be considered as less significant predictive factors of mortality and HF [52]. Growth differentiation factor-15 (GDF-15) has anti-apoptosis effects and elevated levels are important in determining prognosis in HF patients [56]. GDF-15 is one of the members of the transforming growth factor beta cytokine family and is released in response to oxidative stress, inflammation and injury [140]. Although GDF-15 levels are elevated in patients with malignancies, it can also be increased in response to oxidative stress, cellular injury and inflammatory stimuli. No association has been made however between elevated levels of GDF-15 or Galectin-3 and development of cardiotoxicity, hence these markers could just be elevated due to malignancy [56].

\section{MicroRNAs}

Non-coding RNAs (microRNAs) mediate cardiac hypertrophy (microRNA-22, microRNA-495 and several more) [126-128] and fibrosis (microRNA-433) [129], and as such may represent important biomarkers of HF. Also, they can be used to differentiate between reduced and preserved ejection HF, as well as determine prognosis. However, both the variability in measurement as well as an incomplete understanding of their pathological role or specificity means that their use is not currently clinically validated $[130,131]$. microRNA146 a is important in cardiotoxicity related to doxorubicin and is related to activation of apoptotic pathways by downregulation of ErbB4 [132]. It is considered both a predictive and prognostic indicator, not only in cancer but also in a range of pro-inflammatory conditions ranging from Sjogren's syndrome to sepsis [133, 134]. This suggests that microRNAs are an important biomarker of cardiotoxicity presenting with inflammation, but more studies are required.

\section{Insights on Potential New Biomarkers from Genetic Studies}

Genome-wide association studies (GWAS) have been instrumental in identifying single nucleotide polymorphisms to identify patients at increased risk of cardiotoxicity due to anthracycline treatment. The 
largest GWAS involved 1191 patients with HER2-positive breast cancer enrolled in the NCCTG N9831 trial who were treated with anthracyclines and then paclitaxel \pm trastuzumab [135]. It has been shown that the maximum reduction of $\mathrm{LV}$ function has been associated with the following SNPs in those patients treated with trastuzumab: LDB2 (limb domain binding 2), BRINP1 (BMP/retinoic acid inducible neural-specific protein 1, a suppressor of cell cycle progression), RAB22A (a member of the RAS oncogene family which is key in endocytic trafficking), TRPC6 (transient receptor potential cation channel subfamily $\mathrm{C}$ member 6 , involved in cardiac remodelling and hypertrophic cardiomyopathy), LINC01060 (a long intergenic noncoding RNA) and chromosome 6 intergenic region. Another GWAS involved a cohort of 385 patients identified targets which have been confirmed to be present in 181 patients [141]. This includes a SNP near PR domain containing 2, with ZNF domain (PRDM2), which is involved in DNA double-strand break and repair of oxidative stress. In this meta-analysis, this was associated with a decline in LVEF $(p=6.5 \times 10-7)$. Other GWAS have identified RARG (retinoic acid receptor gamma) which is important in cardiotoxicity and can bind to Top $2 \beta$ (involved in anthracycline-related cardiotoxicity) [142]. In this way, GWAS have been shown to be useful in identifying new SNP loci involved in cardiotoxicity, hence paving the way for the identification of new biomarkers. However, causality cannot be inferred from these studies alone, and no validation studies have been carried out to confirm the findings.

A recent study measured the prevalence of cardiomyopathy causing genes in 3 separate oncology cohorts receiving anthracycline or trastuzumab [143]. In the patients who developed cardiotoxicity with significant new LV dysfunction during or after anthracycline or trastuzumab, there was a significantly higher level of background pathogenic cardiomyopathy causing genetic mutations compared with both matched treated unaffected controls and healthy population $(12 \%$ vs $2 \%$ allcause mutations) [143]. Truncating mutations of the Titin gene were enriched in the patients with anthracycline or trastuzumab cardiomyopathy compared with a background population $(7.5 \%$ vs $1.1 \%$ cancer controls and $0.7 \%$ healthy population). Baseline genetic testing may help identify a subpopulation of cancer patients at higher risk who may be eligible for closer surveillance with cardiac biomarkers during and after treatment with anthracycline or trastuzumab, and also may lead to novel biomarkers for risk stratification and surveillance based upon the specific mutation, e.g. myofilament versus mitochondrial versus apoptotic pathways.

\section{Proteomics and Metabolomics}

In a similar way, proteomic or metabolomic technologies hold great potential in the discovery of new biomarkers linked to cardiotoxicity. Low levels of IgE have been linked to the development of cardiotoxicity [144]. Also instead of mass spectroscopy, newer high throughput screening platforms using aptamers (short singlestranded DNA sequences specific to a particular protein) have been developed, which has helped greatly in the development of this technology as biomarkers [145, 146].

\section{Biomarker-Guided Cardioprotective Treatment Strategies}

In clinical practice, it has been shown that angiotensinconverting inhibitors (ACEI) can halt the progression of ventricular dysfunction as a result of anthracycline treatment $[147,148]$. Studies have suggested that the reninangiotensin-aldosterone system is not directly involved in cardiotoxicity, but may be involved in the remodelling process which takes place afterwards. For example, the International CardioOncology Society-One (ICOS-1) trial investigated whether enalapril started in patients receiving anthracyclines either as primary prevention before and during anthracyclines or as a biomarker-guided cardioprotective strategy where enalapril was started after a detection of a troponin rise [149]. The study concluded that low dose enalapril (mean $5 \mathrm{mg}$ /day) did not reduce anthracycline-related rises in troponin, but it did prevent the related adverse LV remodelling in both study arms.

This was also supported by the PRADA trial where primary prevention with candesartan did not prevent troponin rises in breast cancer cohort receiving anthracycline, but it did reduce adverse remodelling [150]. In contrast, data from both the CECCY [151] and PRADA [150] trials showed that beta blockers prescribed before and during anthracycline treatment could reduce the troponin rise observed in the control arm. However, the beta blocker did not prevent adverse remodelling. Therefore, a combination strategy with beta blockers as primary prevention to prevent myocyte injury and RAAS blocker for patients who develop myocyte injury with troponin elevation is a potential strategy from the results so far.

Similarly, the ongoing Cardiac CARE study (ISRCTN24439460) is designed primarily to assess whether biomarker-guided cardioprotection using treatment with highdose ACE inhibitors and beta blockers in breast cancer and lymphoma patients where a high-sensitivity troponin assay is 
used for surveillance [152]. Several studies have shown that a multimodality method involving imaging, as well as biomarkers, is needed. Furthermore, there is evidence to show that the findings are variable depending on whether biomarkers are used pre-, during or post-chemotherapy [46, 74 , 95].

\section{Conclusion}

There is evidence to substantiate the use of troponins as a marker of cardiovascular toxicities, such that elevated troponins during anthracyclines are associated with more adverse outcomes and are a significant marker of cardiac dysfunction [46, 74, 149, 153, 154]. Nevertheless, other studies including ICOS-1 [149] have demonstrated that troponin may not always be the most suitable biomarker by demonstrating that it is possible for it to rise independently of cardiotoxicity. On the other hand, other biomarkers including NPs, microRNA, myeloperoxidase and markers of extracellular matrix turnover, are more specific for detecting both acute and chronic effects of anthracyclines and other chemotherapy regimens. In other targeted cancer therapies including trastuzumab, VEGFi and $\mathrm{Pl}$ treatment surveillance using NPs has more evidence for detecting subclinical LV dysfunction, predating the development of symptoms and signs consistent with HF. Immune-based cancer therapies may cause myocarditis, and troponin is the marker of choice, but emerging new toxicities including late LV dysfunction mean that NPs may also have a role. This field is open for much research into both novel biomarker discovery and to clarify the exact role of the current cardiac biomarkers (troponin and NPs) in diagnosis, surveillance and biomarkerguided cardioprotective treatment. In this way, the use of combinations of biomarkers will be pivotal towards future strategies of defining the extent of the use of cardioprotective measures.

\section{Compliance with Ethical Standards}

Conflict of Interest ARL has received speaker, advisory board or consultancy fees and/or research grants from Pfizer, Novartis, Servier, Amgen,Clinigen Group, Takeda, Roche, Eli Lily, Eisal, Bristol Myers Squibb, Ferring Pharmaceuticals and Boehringer Ingelheim. KA has no conflicts of interest.

Ethical Approval This article does not contain any studies with human participants or animals performed by any of the authors.

\section{Appendix}

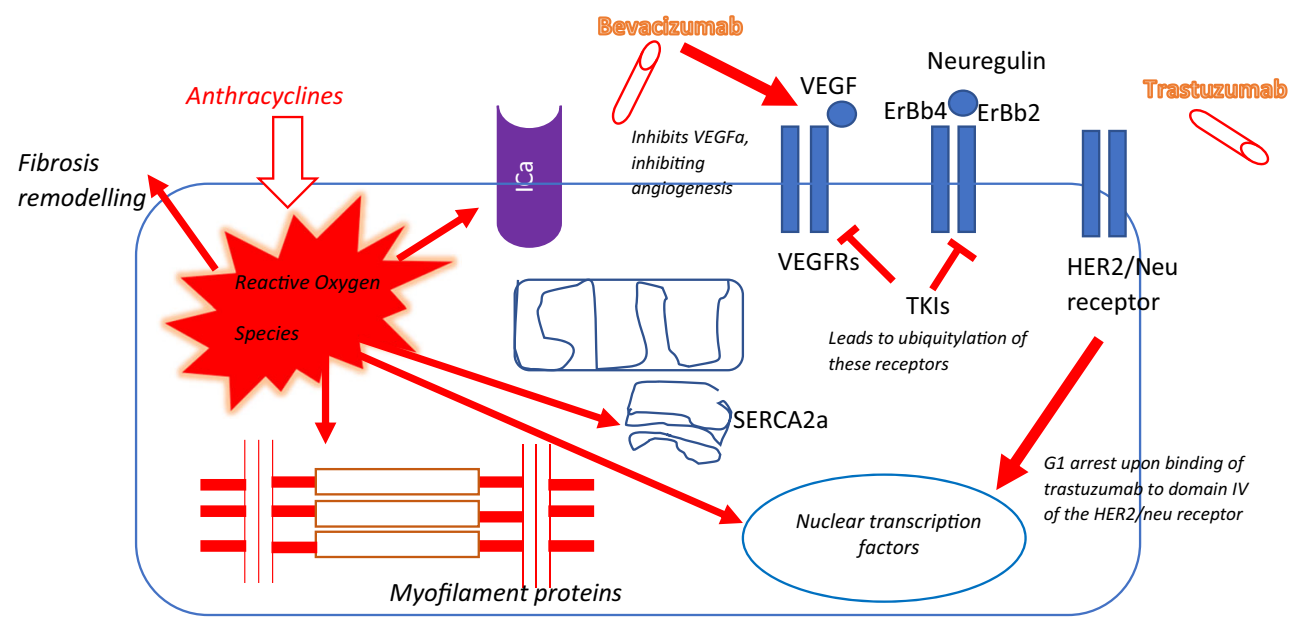

Fig. 1 Demonstrates the main mechanism of cardiotoxicity for most cytotoxic chemotherapy. Firstly, anthracycylines have direct mechanisms of damaging DNA resulting in cell cycle arrest leading to either: apopotosis, cell necrosis or cell autophagy. They also generate toxic reactive oxygen species (ROS). ROS trigger off a cascade of events which alters mitochondrial permeability and hence function which moderates calcium signalling and hence myocyte contraction. The mechansim of this invovles the SERCA2a protein which is at the centre of calcium homeostasis. Secondly the receptor tyrosine kinase inhibitors, namely bevacluzumab, trastuzumab, etc. function by inhibiting the activity of their receptor proteins: Vascular Endothelial Growth Factor Receptor (VEGFR), ErBb4/ErBb2 and Her2/Neu receptor resulting in cell cycle arrest in the Growth 1 (G1) phase of the cycle leading eventually to apoptosis, necrosis or cell autophagy. This transition is mediated by p53 (a nuclear DNA-binding phosphoprotein). $[22,155,156]$ 
Open Access This article is licensed under a Creative Commons Attribution 4.0 International License, which permits use, sharing, adaptation, distribution and reproduction in any medium or format, as long as you give appropriate credit to the original author(s) and the source, provide a link to the Creative Commons licence, and indicate if changes were made. The images or other third party material in this article are included in the article's Creative Commons licence, unless indicated otherwise in a credit line to the material. If material is not included in the article's Creative Commons licence and your intended use is not permitted by statutory regulation or exceeds the permitted use, you will need to obtain permission directly from the copyright holder. To view a copy of this licence, visit http://creativecommons.org/licenses/by/4.0/.

\section{References}

1. Dolci, A., \& Panteghini, M. (2006). The exciting story of cardiac biomarkers: from retrospective detection to gold diagnostic standard for acute myocardial infarction and more. Clinica Chimica Acta, 369(2), 179-187. https://doi.org/10.1016/j.cca.2006.02.042.

2. Zamorano, J. L., Lancellotti, P., Rodriguez, M. D., et al. (2016). 2016 ESC Position Paper on cancer treatments and cardiovascular toxicity developed under the auspices of the ESC Committee for Practice Guidelines. European Heart Journal, 37(36), 27682801. https://doi.org/10.1093/eurheartj/ehw211.

3. Ponikowski, P., Voors, A. A., Anker, S. D., et al. (2016). 2016 ESC Guidelines for the diagnosis and treatment of acute and chronic heart failure: the Task Force for the diagnosis and treatment of acute and chronic heart failure of the European Society of Cardiology (ESC). Developed with the special contribution of the heart failure association (HFA) of the ESC. European Journal of Heart Failure, 18(8), 891-975. https://doi.org/10.1002/ejhf.592.

4. National Cancer Institute. Common Terminology Criteria for Adverse Events (CTCAE).Version 4.0. Available at: http:// ctep.cancer.gov/protocolDevelopment/electronic_applications/ docs/ctcaev4.pdf. Accessed December 25, 2019.

5. Curigliano, G., Lenihan, D., Fradley, M., et al. (2020). Management of cardiac disease in cancer patients throughout oncological treatment: ESMO consensus recommendations. Annals of Oncology, the journal of the European Society for Medical Oncology, 31(2), 171-190. https://doi.org/10.1016/j.annonc. 2019.10.023.

6. McGowan, J. V., Chung, R., Maulik, A., Piotrowska, I., Walker, J. M., \& Yellon, D. M. (2017). Anthracycline chemotherapy and cardiotoxicity. Cardiovascular Drugs and Therapy, 31(1), 6375. https://doi.org/10.1007/s10557-016-6711-0.

7. Feijen, E. A. M., Leisenring, W. M., Stratton, K. L., Ness, K. K., van der Pal, H. J. H., van Dalen, E. C., Armstrong, G. T., Aune, G. J., Green, D. M., Hudson, M. M., Loonen, J., Oeffinger, K. C., Robison, L. L., Yasui, Y., Kremer, L. C. M., \& Chow, E. J. (2019). Derivation of anthracycline and anthraquinone equivalence ratios to doxorubicin for late-onset cardiotoxicity. JAMA Oncology, 5(6), 864.

8. Fallah-Rad, N., Walker, J. R., Wassef, A., et al. (2011). The utility of cardiac biomarkers, tissue velocity and strain imaging, and cardiac magnetic resonance imaging in predicting early left ventricular dysfunction in patients with human epidermal growth factor receptor II-positive breast cancer treated with adjuvant trastuzumab therapy. Journal of the American College of Cardiology, 57(22), 2263-2270. https://doi.org/10.1016/j.jacc. 2010.11.063.

9. Pareek, N., Cevallos, J., Moliner, P., et al. (2018). Activity and outcomes of a cardio-oncology service in the United Kingdom-a five-year experience. European Journal of Heart Failure, 20(12), 1721-1731. https://doi.org/10.1002/ejhf.1292.

10. Moslehi, J. J. (2016). Cardiovascular toxic effects of targeted cancer therapies. The New England Journal of Medicine, 375(15), 1457-1467. https://doi.org/10.1056/NEJMra1100265.

11. Henriksen, P. A. (2018). Anthracycline cardiotoxicity: an update on mechanisms, monitoring and prevention. Heart, 971-977. https://doi.org/10.1136/heartjnl-2017-312103.

12. Nowsheen, S., Aziz, K., Park, J. Y., et al. (2018). Trastuzumab in female breast cancer patients with reduced left ventricular ejection fraction. Journal of the American Heart Association, 7(15). https://doi.org/10.1161/JAHA.118.008637.

13. Abdel-Rahman, O., ElHalawani, H., \& Ahmed, H. (2015). Risk of selected cardiovascular toxicities in patients with cancer treated with MEK inhibitors: a comparative systematic review and meta-analysis. J Glob Oncol, 1(2), 73-82. https://doi.org/10.1200/ jgo.2015.000802.

14. Oyakawa, T., Nakashima, K., \& Naito, T. (2017). Cardiac dysfunction caused by osimertinib. Journal of Thoracic Oncology, e159-e160. https://doi.org/10.1016/j.jtho.2017.05.016.

15. O'Hare, M., Sharma, A., Murphy, K., Mookadam, F., \& Lee, H. (2015). Cardio-oncology part I: chemotherapy and cardiovascular toxicity. Expert Review of Cardiovascular Therapy, 13(5), 511518. https://doi.org/10.1586/14779072.2015.1032940.

16. Lyu, Y. L., Kerrigan, J. E., Lin, C.-P., Azarova, A. M., Tsai, Y.-C., Ban, Y., \& Liu, L. F. (2007). Topoisomerase II mediated DNA double-strand breaks: implications in doxorubicin cardiotoxicity and prevention by dexrazoxane. Cancer Research, 67(18), 88398846.

17. Cardinale, D., Colombo, A., Bacchiani, G., et al. (2015). Early detection of anthracycline cardiotoxicity and improvement with heart failure therapy. Circulation, 131(22), 1981-1988. https:// doi.org/10.1161/CIRCULATIONAHA.114.013777.

18. Shakir, D., \& Rasul, K. I. (2009). Chemotherapy induced cardiomyopathy: pathogenesis, monitoring and management. Journal of Clinical Medical Research, 1(1), 8-12. https://doi.org/10.4021/ jocmr2009.02.1225.

19. Odiete, O., Hill, M. F., \& Sawyer, D. B. (2012). Neuregulin in Cardiovascular Development and Disease. Circulation Research, 111(10), 1376-1385.

20. Sawyer, D. B., Zuppinger, C., Miller, T. A., Eppenberger, H. M., \& Suter, T. M. (2002). Modulation of anthracycline-induced myofibrillar disarray in rat ventricular myocytes by neuregulin-1beta and anti-erbB2: potential mechanism for trastuzumab-induced cardiotoxicity. Circulation, 105(13), 1551-1554.

21. Bian, Y., Sun, M., Silver, M., et al. (2009). Neuregulin-1 attenuated doxorubicin-induced decrease in cardiac troponins. American Journal of Physiology: Heart and Circulatory Physiology, 297(6), H1974-H1983. https://doi.org/10.1152/ajpheart.01010.2008.

22. Molinaro, M., Ameri, P., Marone, G., et al. (2015). Recent advances on pathophysiology, diagnostic and therapeutic insights in cardiac dysfunction induced by antineoplastic drugs. BioMed Research International, 2015, 1-14. https://doi.org/10.1155/ 2015/138148.

23. Sawyer, D. B., Zuppinger, C., Miller, T. A., Eppenberger, H. M., \& Suter, T. M. (2002). Modulation of anthracycline-induced myofibrillar disarray in rat ventricular myocytes by neuregulin-1 $\beta$ and anti-erbB2. Circulation, 105(13), 1551-1554.

24. Maitland, M. L., Bakris, G. L., Black, H. R., et al. (2010). Initial assessment, surveillance, and management of blood pressure in patients receiving vascular endothelial growth factor signaling pathway inhibitors. Journal of the National Cancer Institute, 102(9), 596-604. https://doi.org/10.1093/jnci/djq091.

25. Miller, G. D., Bruno, B. J., \& Lim, C. S. (2014). Resistant mutations in CML and $\mathrm{Ph}(+) \mathrm{ALL}$ - role of ponatinib. Biologics, 8, 
243-254. Published 2014 Oct 20. https://doi.org/10.2147/BTT. S50734.

26. Scappaticci, F. A., Skillings, J. R., Holden, S. N., et al. (2007). Arterial thromboembolic events in patients with metastatic carcinoma treated with chemotherapy and bevacizumab. Journal of the National Cancer Institute, 99(16), 1232-1239. https://doi.org/10. 1093/jnci/djm086.

27. Choueiri, T. K., Schutz, F. A. B., Je, Y., Rosenberg, J. E., \& Bellmunt, J. (2010). Risk of arterial thromboembolic events with sunitinib and sorafenib: a systematic review and meta-analysis of clinical trials. Journal of Clinical Oncology, 28(13), 2280-2285. https://doi.org/10.1200/JCO.2009.27.2757.

28. Ghatalia, P., Je, Y., Kaymakcalan, M. D., Sonpavde, G., \& Choueiri, T. K. (2015). QTc interval prolongation with vascular endothelial growth factor receptor tyrosine kinase inhibitors. British Journal of Cancer, 112(2), 296-305. https://doi.org/10. 1038/bjc.2014.564.

29. Ghatalia, P., Morgan, C. J., Je, Y., et al. (2015). Congestive heart failure with vascular endothelial growth factor receptor tyrosine kinase inhibitors. Critical Reviews in Oncology/Hematology, 94(2), 228-237. https://doi.org/10.1016/j.critrevonc.2014.12.008.

30. Schutz, F. A. B., Je, Y., Richards, C. J., \& Choueiri, T. K. (2012). Meta-analysis of randomized controlled trials for the incidence and risk of treatment-related mortality in patients with cancer treated with vascular endothelial growth factor tyrosine kinase inhibitors. Journal of Clinical Oncology, 30(8), 871-877. https://doi. org/10.1200/JCO.2011.37.1195.

31. Aparicio-Gallego, G., Afonso-Afonso, F. J., León-Mateos, L., et al. (2011). Molecular basis of hypertension side effects induced by sunitinib. Anti-Cancer Drugs, 22(1), 1-8. https://doi.org/10.1097/ CAD.0b013e3283403806.

32. Eremina, V., Jefferson, J. A., Kowalewska, J., et al. (2008). VEGF inhibition and renal thrombotic microangiopathy. The New England Journal of Medicine, 358(11), 1129-1136. https://doi. org/10.1056/NEJMoa0707330.

33. Rini, B. I., Cohen, D. P., Lu, D. R., et al. (2011). Hypertension as a biomarker of efficacy in patients with metastatic renal cell carcinoma treated with sunitinib. Journal of the National Cancer Institute, 103(9), 763-773. https://doi.org/10.1093/jnci/djr128.

34. Meyer, T., Robles-Carrillo, L., Robson, T., et al. (2009). Bevacizumab immune complexes activate platelets and induce thrombosis in FCGR2A transgenic mice. Journal of Thrombosis and Haemostasis, 7(1), 171-181. https://doi.org/10.1111/j.15387836.2008.03212.x.

35. Hong, S., Fang, W., Liang, W., et al. (2014). Risk of treatmentrelated deaths with vascular endothelial growth factor receptor tyrosine kinase inhibitors: a meta-analysis of 41 randomized controlled trials. OncoTargets and Therapy, 7, 1851-1867. https:// doi.org/10.2147/OTT.S68386.

36. Hall, P. S., Harshman, L. C., Srinivas, S., \& Witteles, R. M. (2013). The frequency and severity of cardiovascular toxicity from targeted therapy in advanced renal cell carcinoma patients. JACC: Heart Failure, 1(1), 72-78. https://doi.org/10.1016/j.jchf. 2012.09.001.

37. Catino, A. B., Hubbard, R. A., Chirinos, J. A., et al. (2018). Longitudinal assessment of vascular function with sunitinib in patients with metastatic renal cell carcinoma. Circulation. Heart Failure, 11(3), e004408. https://doi.org/10.1161/ CIRCHEARTFAILURE.117.004408.

38. Jain, V., Bahia, J., Mohebtash, M., \& Barac, A. (2017). Cardiovascular complications associated with novel cancer immunotherapies. Current Treatment Options in Cardiovascular Medicine, 19(5), 36. https://doi.org/10.1007/s11936-017-0532-8.

39. Touyz, R. M., \& Herrmann, J. (2018). Cardiotoxicity with vascular endothelial growth factor inhibitor therapy. JCO Precision Oncology, 2(1), 13. https://doi.org/10.1038/s41698-018-0056-Z.
40. Lenihan, D. (2017). Cardio-oncology: what is the best practice we can all strive for? International Journal of Cardiology, 241, 393 394. https://doi.org/10.1016/j.ijcard.2017.03.136.

41. Guha, A., Armanious, M., \& Fradley, M. G. (2019). Update on cardio-oncology: novel cancer therapeutics and associated cardiotoxicities. Trends in Cardiovascular Medicine, 29(1), 2939. https://doi.org/10.1016/j.tcm.2018.06.001.

42. Burstein, D. S., Maude, S., Grupp, S., Griffis, H., Rossano, J., \& Lin, K. (2018). Cardiac profile of chimeric antigen receptor T cell therapy in children: A single-institution experience. Biology of Blood and Marrow Transplantation, 24(8), 1590-1595. https:// doi.org/10.1016/j.bbmt.2018.05.014.

43. Alvi, R. M., Frigault, M. J., Fradley, M. G., et al. (2019). Cardiovascular events among adults treated with chimeric antigen receptor T-cells (CAR-T). Journal of the American College of Cardiology, 74(25), 3099-3108. https://doi.org/10.1016/j.jacc. 2019.10.038.

44. Plana, J. C., Galderisi, M., Barac, A., et al. (2014). Expert consensus for multimodality imaging evaluation of adult patients during and after cancer therapy: a report from the American Society of Echocardiography and the European Association of Cardiovascular Imaging. Journal of the American Society of Echocardiography, 27(9), 911-939. https://doi.org/10.1016/j. echo.2014.07.012.

45. Omland, T., de Lemos, J. A., Sabatine, M. S., et al. (2009). A sensitive cardiac troponin $\mathrm{T}$ assay in stable coronary artery disease. The New England Journal of Medicine, 361(26), 2538 2547. https://doi.org/10.1056/NEJMoa0805299.

46. Cardinale, D., Sandri, M. T., Martinoni, A., et al. (2000). Left ventricular dysfunction predicted by early troponin I release after high-dose chemotherapy. Journal of the American College of Cardiology, 36(2), 517-522.

47. Cardinale, D., Sandri, M. T., Colombo, A., et al. (2004). Prognostic value of troponin I in cardiac risk stratification of cancer patients undergoing high-dose chemotherapy. Circulation, 109(22), 2749-2754. https://doi.org/10.1161/01.CIR. 0000130926.51766.CC.

48. Cardinale, D., Colombo, A., Torrisi, R., et al. (2010). Trastuzumab-induced cardiotoxicity: clinical and prognostic implications of troponin I evaluation. Journal of Clinical Oncology, 28(25), 3910-3916. https://doi.org/10.1200/JCO.2009.27.3615.

49. Welsh, P., Preiss, D., Hayward, C., et al. (2019). Cardiac troponin $\mathrm{T}$ and troponin $\mathrm{i}$ in the general population: comparing and contrasting their genetic determinants and associations with outcomes. Circulation, 139(24), 2754-2764. https://doi.org/10. 1161/CIRCULATIONAHA.118.038529.

50. Sawaya, H., Sebag, I. A., Plana, J. C., et al. (2011). Early detection and prediction of cardiotoxicity in chemotherapy-treated patients. The American Journal of Cardiology, 107(9), 1375-1380. https:// doi.org/10.1016/j.amjcard.2011.01.006.

51. Lipshultz, S. E., Scully, R. E., Lipsitz, S. R., et al. (2010). Assessment of dexrazoxane as a cardioprotectant in doxorubicin-treated children with high-risk acute lymphoblastic leukaemia: long-term follow-up of a prospective, randomised, multicentre trial. The Lancet Oncology, 11(10), 950-961. https://doi.org/10. 1016/S1470-2045(10)70204-7.

52. Sawaya, H., Sebag, I. A., Plana, J. C., et al. (2012). Assessment of echocardiography and biomarkers for the extended prediction of cardiotoxicity in patients treated with anthracyclines, taxanes, and trastuzumab. Circulation. Cardiovascular Imaging, 5(5), 596603. https://doi.org/10.1161/CIRCIMAGING.112.973321.

53. Drafts, B. C., Twomley, K. M., D’Agostino, R., et al. (2013). Low to moderate dose anthracycline-based chemotherapy is associated with early noninvasive imaging evidence of subclinical cardiovascular disease. JACC: Cardiovascular Imaging, 6(8), 877-885. https://doi.org/10.1016/j.jcmg.2012.11.017. 
54. Mornoș, C., \& Petrescu, L. (2013). Early detection of anthracycline-mediated cardiotoxicity: the value of considering both global longitudinal left ventricular strain and twist. Canadian Journal of Physiology and Pharmacology, 91(8), 601-607. https://doi.org/10.1139/cjpp-2012-0398.

55. Mavinkurve-Groothuis, A. M. C., Marcus, K. A., Pourier, M., et al. (2013). Myocardial 2D strain echocardiography and cardiac biomarkers in children during and shortly after anthracycline therapy for acute lymphoblastic leukaemia (ALL): a prospective study. European Heart Journal Cardiovascular Imaging, 14(6), 562-569. https://doi.org/10.1093/ehjci/jes217.

56. Ky, B., Putt, M., Sawaya, H., et al. (2014). Early increases in multiple biomarkers predict subsequent cardiotoxicity in patients with breast cancer treated with doxorubicin, taxanes, and trastuzumab. Journal of the American College of Cardiology, 63(8), 809-816. https://doi.org/10.1016/j.jacc.2013.10.061.

57. Putt, M., Hahn, V. S., Januzzi, J. L., et al. (2015). Longitudinal changes in multiple biomarkers are associated with cardiotoxicity in breast cancer patients treated with doxorubicin, taxanes, and trastuzumab. Clinical Chemistry, 61(9), 1164-1172. https://doi. org/10.1373/clinchem.2015.241232.

58. Olivieri, J., Perna, G. P., Bocci, C., et al. (2017). Modern management of anthracycline-induced cardiotoxicity in lymphoma patients: low occurrence of cardiotoxicity with comprehensive assessment and tailored substitution by nonpegylated liposomal doxorubicin. Oncologist, 22(4), 422-431. https://doi.org/10. 1634/theoncologist.2016-0289.

59. Kitayama, H., Kondo, T., Sugiyama, J., et al. (2017). High-sensitive troponin $\mathrm{T}$ assay can predict anthracycline- and trastuzumabinduced cardiotoxicity in breast cancer patients. Breast Cancer, 24(6), 774-782. https://doi.org/10.1007/s12282-017-0778-8.

60. Shafi, A., Siddiqui, N., Imtiaz, S., \& Din Sajid, M. U. (2017). Left ventricular systolic dysfunction predicted by early troponin I release after anthracycline based chemotherapy in breast cancer patients. Journal of Ayub Medical College, Abbottabad, 29(2), 266269.

61. Lipshultz, S. E., Rifai, N., Sallan, S. E., et al. (1997). Predictive value of cardiac troponin $\mathrm{T}$ in pediatric patients at risk for myocardial injury. Circulation, 96(8), 2641-2648.

62. Auner, H. W., Tinchon, C., Linkesch, W., et al. (2003). Prolonged monitoring of troponin $\mathrm{T}$ for the detection of anthracycline cardiotoxicity in adults with hematological malignancies. Annals of Hematology, 82(4), 218-222. https://doi.org/10.1007/s00277003-0615-3.

63. Sandri, M. T., Cardinale, D., Zorzino, L., et al. (2003). Minor increases in plasma troponin I predict decreased left ventricular ejection fraction after high-dose chemotherapy. Clinical Chemistry, 49(2), 248-252.

64. Specchia, G., Buquicchio, C., Pansini, N., et al. (2005). Monitoring of cardiac function on the basis of serum troponin I levels in patients with acute leukemia treated with anthracyclines. The Journal of Laboratory and Clinical Medicine, 145(4), 212220.

65. Kilickap, S., Barista, I., Akgul, E., et al. (2005). cTnT can be a useful marker for early detection of anthracycline cardiotoxicity. Annals of Oncology, 16(5), 798-804. https://doi.org/10.1093/ annonc/mdi152.

66. Lee, H. S., Son, C. B., Shin, S. H., \& Kim, Y. S. (2008). Clinical correlation between brain natriutetic peptide and anthracyclin-induced cardiac toxicity. Cancer Research and Treatment, 40(3), 121. https://doi.org/10.4143/crt.2008.40.3.121.

67. Schmidinger, M., Zielinski, C. C., Vogl, U. M., et al. (2008). Cardiac toxicity of sunitinib and sorafenib in patients with metastatic renal cell carcinoma. Journal of Clinical Oncology, 26(32), 5204-5212. https://doi.org/10.1200/JCO.2007.15.6331.
68. Ylänen, K., Poutanen, T., Savukoski, T., Eerola, A., \& Vettenranta, K. (2015). Cardiac biomarkers indicate a need for sensitive cardiac imaging among long-term childhood cancer survivors exposed to anthracyclines. Acta Paediatrica, 104(3), 313319. https://doi.org/10.1111/apa.12862.

69. Mavinkurve-Groothuis, A. M. C., Groot-Loonen, J., Bellersen, L., et al. (2009). Abnormal NT-pro-BNP levels in asymptomatic long-term survivors of childhood cancer treated with anthracyclines. Pediatric Blood \& Cancer, 52(5), 631-636. https://doi.org/10.1002/pbc.21913.

70. Pourier, M. S., Kapusta, L., van Gennip, A., et al. (2015). Values of high sensitive troponin $\mathrm{T}$ in long-term survivors of childhood cancer treated with anthracyclines. Clinica Chimica Acta, 441, 29-32. https://doi.org/10.1016/j.cca.2014.12.011.

71. Zardavas, D., Suter, T. M., Van Veldhuisen, D. J., et al. (2017). Role of troponins I and $\mathrm{T}$ and $\mathrm{N}$-terminal prohormone of brain natriuretic peptide in monitoring cardiac safety of patients with early-stage human epidermal growth factor receptor 2-positive breast cancer receiving trastuzumab: a herceptin adjuvant study cardiac marker substudy. Journal of Clinical Oncology, 35(8), 878-884. https://doi.org/10.1200/JCO.2015.65.7916.

72. Christenson, E. S., James, T., Agrawal, V., \& Park, B. H. (2015). Use of biomarkers for the assessment of chemotherapy-induced cardiac toxicity. Clinical Biochemistry, 48(4-5), 223-235. https:// doi.org/10.1016/j.clinbiochem.2014.10.013.

73. Cardinale, D., Biasillo, G., \& Cipolla, C. M. (2016). Curing cancer, saving the heart: a challenge that cardioncology should not miss. Current Cardiology Reports, 18(6), 51. https://doi.org/10. 1007/s11886-016-0731-z.

74. Cardinale, D., Biasillo, G., Salvatici, M., Sandri, M. T., \& Cipolla, C. M. (2017). Using biomarkers to predict and to prevent cardiotoxicity of cancer therapy. Expert Review of Molecular Diagnostics, 17(3), 245-256. https://doi.org/10.1080/14737159. 2017.1283219.

75. Mulrooney, D. A., Yeazel, M. W., Kawashima, T., Mertens, A. C., Mitby, P., Stovall, M., Donaldson, S. S., Green, D. M., Sklar, C. A., Robison, L. L., \& Leisenring, W. M. (2009). Cardiac outcomes in a cohort of adult survivors of childhood and adolescent cancer: retrospective analysis of the Childhood Cancer Survivor Study cohort. BMJ, 339(dec08 1), b4606.

76. Tukenova, M., Guibout, C., Oberlin, O., Doyon, F., Mousannif, A., Haddy, N., Guérin, S., Pacquement, H., Aouba, A., Hawkins, M., Winter, D., Bourhis, J., Lefkopoulos, D., Diallo, I., \& de Vathaire, F. (2010). Role of cancer treatment in long-term overall and cardiovascular mortality after childhood cancer. Journal of Clinical Oncology, 28(8), 1308-1315.

77. Armstrong, G. T., Liu, Q., Yasui, Y., Neglia, J. P., Leisenring, W., Robison, L. L., \& Mertens, A. C. (2009). Late mortality among 5year survivors of childhood cancer: a summary from the childhood cancer survivor study. Journal of Clinical Oncology, 27(14), 2328-2338.

78. Pardoll, D. M. (2012). The blockade of immune checkpoints in cancer immunotherapy. Nature Reviews. Cancer, 12(4), 252-264. https://doi.org/10.1038/nrc3239.

79. Mahmood, S. S., Fradley, M. G., Cohen, J. V., et al. (2018). Myocarditis in patients treated with immune checkpoint inhibitors. Journal of the American College of Cardiology, 71(16), 1755-1764. https://doi.org/10.1016/j.jacc.2018.02.037.

80. Bonaca, M. P., Olenchock, B. A., Salem, J. E., et al. (2019). Myocarditis in the setting of cancer therapeutics: proposed case definitions for emerging clinical syndromes in cardio-oncology. Circulation, 140(1), 80-91. https://doi.org/10.1161/ CIRCULATIONAHA.118.034497.

81. Lyon, A. R., Yousaf, N., Battisti, N. M. L., Moslehi, J., \& Larkin, J. (2018). Immune checkpoint inhibitors and cardiovascular 
toxicity. The Lancet Oncology, e447-e458. https://doi.org/10. 1016/S1470-2045(18)30457-1.

82. Johnson, D. B., Balko, J. M., Compton, M. L., et al. (2016). Fulminant myocarditis with combination immune checkpoint blockade. The New England Journal of Medicine, 375(18), 1749-1755. https://doi.org/10.1056/NEJMoa1609214.

83. Lee, D. W., Gardner, R., Porter, D. L., Louis, C. U., Ahmed, N., Jensen, M., Grupp, S. A., \& Mackall, C. L. (2014). Current concepts in the diagnosis and management of cytokine release syndrome. Blood, 124(2), 188-195.

84. Daugaard, G., Lassen, U., Bie, P., et al. (2005). Natriuretic peptides in the monitoring of anthracycline induced reduction in left ventricular ejection fraction. European Journal of Heart Failure, 7(1), 87-93. https://doi.org/10.1016/j.ejheart.2004.03.009.

85. Lenihan, D. J., Massey, M. R., Baysinger, K. B., et al. (2007). Superior detection of cardiotoxicity during chemotherapy using biomarkers. Journal of Cardiac Failure, 13(6), S151. https://doi. org/10.1016/j.cardfail.2007.06.634.

86. Dodos, F., Halbsguth, T., Erdmann, E., \& Hoppe, U. C. (2008). Usefulness of myocardial performance index and biochemical markers for early detection of anthracycline-induced cardiotoxicity in adults. Clinical Research in Cardiology, 97(5), 318-326. https://doi.org/10.1007/s00392-007-0633-6.

87. De Iuliis, F., Salerno, G., Taglieri, L., De Biase, L., Lanza, R., Cardelli, P., \& Scarpa, S. (2016). Serum biomarkers evaluation to predict chemotherapy-induced cardiotoxicity in breast cancer patients. Tumor Biology, 37(3), 3379-3387.

88. Sandri, M. T., Salvatici, M., Cardinale, D., Zorzino, L., Passerini, R., Lentati, P., Leon, M., Civelli, M., Martinelli, G., \& Cipolla, C. M. (2005). N-terminal Pro-B-type natriuretic peptide after highdose chemotherapy: a marker predictive of cardiac dysfunction? Clinical Chemistry, 51(8), 1405-1410.

89. Mukoyama, M., Nakao, K., Hosoda, K., et al. (1991). Brain natriuretic peptide as a novel cardiac hormone in humans. Evidence for an exquisite dual natriuretic peptide system, atrial natriuretic peptide and brain natriuretic peptide. Journal of Clinical Investigation, 87, 1402-1412.

90. Kjaer, A., \& Hesse, B. (2001). Heart failure and neuroendocrine activation: diagnostic, prognostic and therapeutic perspectives. Clinical Physiology, 21(6), 661-672.

91. Romano, S., Fratini, S., Ricevuto, E., et al. (2011). Serial measurements of NT-proBNP are predictive of not-high-dose anthracycline cardiotoxicity in breast cancer patients. British Journal of Cancer, 105(11), 1663-1668. https://doi.org/10.1038/ bjc.2011.439.

92. Lenihan, D. J., Stevens, P. L., Massey, M., et al. (2016). The utility of point-of-care biomarkers to detect cardiotoxicity during anthracycline chemotherapy: a feasibility study. Journal of Cardiac Failure, 22(6), 433-438. https://doi.org/10.1016/j. cardfail.2016.04.003.

93. Wieshammer, S., Dreyhaupt, J., Müller, D., Momm, F., \& Jakob, A. (2016). Limitations of N-terminal pro-B-type natriuretic peptide in the diagnosis of heart disease among cancer patients who present with cardiac or pulmonary symptoms. Oncology, 90(3), 143-150. https://doi.org/10.1159/000443505.

94. Pavo, N., Raderer, M., Hülsmann, M., et al. (2015). Cardiovascular biomarkers in patients with cancer and their association with all-cause mortality. Heart, 101(23), 1874-1880. https://doi.org/10.1136/heartjnl-2015-307848.

95. Sandri, M. T., Salvatici, M., Cardinale, D., et al. (2005). N-terminal pro-B-type natriuretic peptide after high-dose chemotherapy: a marker predictive of cardiac dysfunction? Clinical Chemistry, 51(8), 1405-1410. https://doi.org/10.1373/clinchem.2005. 050153 .

96. Hayakawa, H., Komada, Y., Hirayama, M., Hori, H., Ito, M., \& Sakurai, M. (2001). Plasma levels of natriuretic peptides in relation to doxorubicin-induced cardiotoxicity and cardiac function in children with cancer. Medical and Pediatric Oncology, 37(1), 4-9. https://doi.org/10.1002/mpo.1155.

97. Palumbo, I., Palumbo, B., Fravolini, M. L., et al. (2016). Brain natriuretic peptide as a cardiac marker of transient radiotherapyrelated damage in left-sided breast cancer patients: a prospective study. Breast, 25, 45-50. https://doi.org/10.1016/j.breast.2015.10. 004.

98. Cornell, R. F., Ky, B., Weiss, B. M., et al. (2019). Prospective study of cardiac events during proteasome inhibitor therapy for relapsed multiple myeloma. Journal of Clinical Oncology, 37(22), 1946-1955. https://doi.org/10.1200/JCO.19.00231.

99. Cowie, M. (2003). Clinical applications of B-type natriuretic peptide (BNP) testing. European Heart Journal, 24(19), 1710-1718. https://doi.org/10.1016/S0195-668X(03)00476-7.

100. Galasko, G. I. W., Lahiri, A., Barnes, S. C., Collinson, P., \& Senior, R. (2005). What is the normal range for N-terminal probrain natriuretic peptide? How well does this normal range screen for cardiovascular disease? European Heart Journal, 26(21), 2269-2276. https://doi.org/10.1093/eurheartj/ehi410.

101. Takase, H., \& Dohi, Y. (2014). Kidney function crucially affects B-type natriuretic peptide (BNP), N-terminal proBNP and their relationship. European Journal of Clinical Investigation, 44(3), 303-308. https://doi.org/10.1111/eci.12234.

102. Bando, S., Soeki, T., Matsuura, T., et al. (2017). Plasma brain natriuretic peptide levels are elevated in patients with cancer. PLoS One, 12(6), e0178607. https://doi.org/10.1371/journal. pone. 0178607 .

103. Mair, J., Artner-Dworzak, E., Lechleitner, P., Smidt, J., Wagner, I., Dienstl, F., \& Puschendorf, B. (1991). Cardiac troponin T in diagnosis of acute myocardial infarction. Clinical Chemistry, $37(6), 845-852$.

104. Katus, H. A., Remppis, A., Neumann, F. J., Scheffold, T., Diederich, K. W., Vinar, G., Noe, A., Matern, G., \& Kuebler, W. (1991). Diagnostic efficiency of troponin T measurements in acute myocardial infarction. Circulation, 83(3), 902-912.

105. Cardinale, D., Sandri, M. T., Martinoni, A., Borghini, E., Civelli, M., Lamantia, G., Cinieri, S., Martinelli, G., Fiorentini, C., \& Cipolla, C. M. (2002). Myocardial injury revealed by plasma troponin I in breast cancer treated with high-dose chemotherapy. Annals of Oncology, 13(5), 710-715.

106. Lipshultz, S. E., Rifai, N., Dalton, V. M., Levy, D. E., Silverman, L. B., Lipsitz, S. R., Colan, S. D., Asselin, B. L., Barr, R. D., Clavell, L. A., Hurwitz, C. A., Moghrabi, A., Samson, Y., Schorin, M. A., Gelber, R. D., \& Sallan, S. E. (2004). The effect of dexrazoxane on myocardial injury in doxorubicin-treated children with acute lymphoblastic leukemia. New England Journal of Medicine, 351(2), 145-153.

107. Rosenberg S., De Vita V., DeVita, L.T. (2015). Hellman, and Rosenberg's Cancer: Principles \& Practice of Oncology.

108. Libby, P. (2006). Inflammation and cardiovascular disease mechanisms. The American Journal of Clinical Nutrition, 83(2), 456S460S. https://doi.org/10.1093/ajcn/83.2.456S.

109. Hartman, J., \& Frishman, W. H. (2014). Inflammation and atherosclerosis: a review of the role of interleukin- 6 in the development of atherosclerosis and the potential for targeted drug therapy. Cardiology in Review, 22(3), 147-151. https://doi.org/10.1097/ CRD.0000000000000021.

110. Ridker, P. M., \& Lüscher, T. F. (2014). Anti-inflammatory therapies for cardiovascular disease. European Heart Journal, 35(27), 1782-1791. https://doi.org/10.1093/eurheartj/ehu203.

111. Onitilo, A. A., Engel, J. M., Stankowski, R. V., Liang, H., Berg, R. L., \& Doi, S. A. R. (2012). High-sensitivity C-reactive protein (hsCRP) as a biomarker for trastuzumab-induced cardiotoxicity in HER2-positive early-stage breast cancer: a pilot study. Breast 
Cancer Research and Treatment, 134(1), 291-298. https://doi. org/10.1007/s10549-012-2039-z.

112. Lee, D. W., Gardner, R., Porter, D. L., et al. (2014). Current concepts in the diagnosis and management of cytokine release syndrome. Blood, 124(2), 188-195. https://doi.org/10.1182/ blood-2014-05-552729.

113. Frantz, S., Falcao-Pires, I., Balligand, J.-L., et al. (2018). The innate immune system in chronic cardiomyopathy: a European Society of Cardiology (ESC) scientific statement from the Working Group on Myocardial Function of the ESC. European Journal of Heart Failure, 20(3), 445-459. https://doi.org/10. 1002/ejhf.1138.

114. Zhang, Y., Huang, Z., \& Li, H. (2017). Insights into innate immune signalling in controlling cardiac remodelling. Cardiovascular Research, 113(13), 1538-1550. https://doi.org/ 10.1093/cvr/cvx130.

115. Hofmann, U., \& Frantz, S. (2015). Role of lymphocytes in myocardial injury, healing, and remodeling after myocardial infarction. Circulation Research, 116(2), 354-367. https://doi.org/10.1161/ CIRCRESAHA.116.304072.

116. Meng, X., Yang, J., Dong, M., et al. (2016). Regulatory T cells in cardiovascular diseases. Nature Reviews. Cardiology, 13(3), 167179. https://doi.org/10.1038/nrcardio.2015.169.

117. Nahrendorf, M., Frantz, S., Swirski, F. K., et al. (2015). Imaging systemic inflammatory networks in ischemic heart disease. Journal of the American College of Cardiology, 65(15), 15831591. https://doi.org/10.1016/j.jacc.2015.02.034.

118. Baldus, S., Heeschen, C., Meinertz, T., et al. (2003). Myeloperoxidase serum levels predict risk in patients with acute coronary syndromes. Circulation, 108(12), 1440-1445. https:// doi.org/10.1161/01.CIR.0000090690.67322.51.

119. Reichlin, T., Socrates, T., Egli, P., et al. (2010). Use of myeloperoxidase for risk stratification in acute heart failure. Clinical Chemistry, 56(6), 944-951. https://doi.org/10.1373/ clinchem.2009.142257.

120. Hampton, M. B., Kettle, A. J., \& Winterbourn, C. C. (1998). Inside the neutrophil phagosome: oxidants, myeloperoxidase, and bacterial killing. Blood, 92(9), 3007-3017.

121. Mukhopadhyay, P., Rajesh, M., Bátkai, S., et al. (2009). Role of superoxide, nitric oxide, and peroxynitrite in doxorubicin-induced cell death in vivo and in vitro. American Journal of Physiology. Heart and Circulatory Physiology, 296(5), H1466-H1483. https://doi.org/10.1152/ajpheart.00795.2008.

122. Anatoliotakis, N., Deftereos, S., Bouras, G., et al. (2013). Myeloperoxidase: expressing inflammation and oxidative stress in cardiovascular disease. Current Topics in Medicinal Chemistry, 13(2), 115-138.

123. van Boxtel, W., Bulten, B. F., Mavinkurve-Groothuis, A. M. C., et al. (2015). New biomarkers for early detection of cardiotoxicity after treatment with docetaxel, doxorubicin and cyclophosphamide. Biomarkers, 20(2), 143-148. https://doi.org/10.3109/ 1354750X.2015.1040839.

124. Chen, A., Hou, W., Zhang, Y., Chen, Y., \& He, B. (2015). Prognostic value of serum galectin-3 in patients with heart failure: a meta-analysis. International Journal of Cardiology, 182, 168170. https://doi.org/10.1016/j.ijcard.2014.12.137.

125. Schindler, E. I., Szymanski, J. J., Hock, K. G., Geltman, E. M., \& Scott, M. G. (2016). Short- and long-term biologic variability of galectin-3 and other cardiac biomarkers in patients with stable heart failure and healthy adults. Clinical Chemistry, 62(2), 360366. https://doi.org/10.1373/clinchem.2015.246553.

126. Fu, J., Chen, Y., \& Li, F. (2018). Attenuation of MicroRNA-495 derepressed PTEN to effectively protect rat cardiomyocytes from hypertrophy. Cardiol, 139(4), 245-254. https://doi.org/10.1159/ 000487044
127. Huang, Z. P., Chen, J., Seok, H. Y., et al. (2013). MicroRNA-22 regulates cardiac hypertrophy and remodeling in response to stress. Circulation Research, 112(9), 1234-1243. https://doi.org/ 10.1161/CIRCRESAHA.112.300682.

128. Colpaert, R. M. W., \& Calore, M. (2019). MicroRNAs in cardiac diseases. Cells, 8(7), 737. https://doi.org/10.3390/cells8070737.

129. Tao, L., Bei, Y., Chen, P., et al. (2016). Crucial role of miR-433 in regulating cardiac fibrosis. Theranostics, 6(12), 2068-2083. https://doi.org/10.7150/thno.15007.

130. Fichtlscherer, S., Zeiher, A. M., \& Dimmeler, S. (2011). Circulating MicroRNAs. Arteriosclerosis, Thrombosis, and Vascular Biology, 31(11), 2383-2390. https://doi.org/10.1161/ ATVBAHA.111.226696.

131. Mendell, J. T., \& Olson, E. N. (2012). MicroRNAs in stress signaling and human disease. Cell, 148(6), 1172-1187. https://oi. org/10.1016/j.cell.2012.02.005.

132. Horie, T., Ono, K., Nishi, H., et al. (2010). Acute doxorubicin cardiotoxicity is associated with miR-146a-induced inhibition of the neuregulin-ErbB pathway. Cardiovascular Research, 87(4), 656-664. https://doi.org/10.1093/cvr/cvq148.

133. Wang, J., Yu, M., Yu, G., et al. (2010). Serum miR-146a and miR223 as potential new biomarkers for sepsis. Biochemical and Biophysical Research Communications, 394(1), 184-188. https://doi.org/10.1016/j.bbrc.2010.02.145.

134. Brase, J. C., Wuttig, D., Kuner, R., \& Sültmann, H. (2010). Serum microRNAs as non-invasive biomarkers for cancer. Molecular Cancer, 9(1), 306. https://doi.org/10.1186/1476-4598-9-306.

135. Serie, D. J., Crook, J. E., Necela, B. M., et al. (2017). Genomewide association study of cardiotoxicity in the NCCTG N9831 (Alliance) adjuvant trastuzumab trial. Pharmacogenetics and Genomics, 27(10), 378-385. https://doi.org/10.1097/FPC. 0000000000000302 .

136. Haney, S., Cresti, N., Verrill, M., \& Plummer, C. J. (2013). Cardiac troponin release following standard dose anthracyclinebased adjuvant chemotherapy. European Heart Journal, 34(suppl 1), P5752-P5752.

137. Katsurada, K., Ichida, M., Sakuragi, M., Takehara, M., Hozumi, Y., \& Kario, K. (2014). High-sensitivity troponin T as a marker to predict cardiotoxicity in breast cancer patients with adjuvant trastuzumab therapy. SpringerPlus, 3(1), 620.

138. Groenning, B. A., Nilsson, J. C., Sondergaard, L., Kjaer, A., Larsson, H. B. W., \& Hildebrandt, P. R. (2001). Evaluation of impaired left ventricular ejection fraction and increased dimensions by multiple neurohumoral plasma concentrations. European Journal of Heart Failure, 3(6), 699-708.

139. Morris, P. G., Chen, C., Steingart, R., Fleisher, M., Lin, N., Moy, B., Come, S., Sugarman, S., Abbruzzi, A., Lehman, R., Patil, S., Dickler, M., McArthur, H. L., Winer, E., Norton, L., Hudis, C. A., \& Dang, C. T. (2011). Troponin I and C-reactive protein are commonly detected in patients with breast cancer treated with dosedense chemotherapy incorporating trastuzumab and lapatinib. Clinical Cancer Research, 17(10), 3490-3499.

140. Wollert, K. C., Kempf, T., Lagerqvist, B., Lindahl, B., Olofsson, S., Allhoff, T., Peter, T., Siegbahn, A., Venge, P., Drexler, H., \& Wallentin, L. (2007). Growth differentiation factor 15 for risk stratification and selection of an invasive treatment strategy in non-ST-elevation acute coronary syndrome. Circulation, 116(14), 1540-1548.

141. Wells, Q. S., Veatch, O. J., Fessel, J. P., et al. (2017). Genomewide association and pathway analysis of left ventricular function after anthracycline exposure in adults. Pharmacogenetics and Genomics, 27(7), 247-254. https://doi.org/10.1097/FPC. 0000000000000284 .

142. Aminkeng, F., Bhavsar, A. P., Visscher, H., et al. (2015). A coding variant in RARG confers susceptibility to anthracycline-induced 
cardiotoxicity in childhood cancer. Nature Genetics, 47(9), 10791084. https://doi.org/10.1038/ng.3374.

143. Garcia-Pavia, P., Kim, Y., Restrepo-Cordoba, M. A., et al. (2019). Genetic variants associated with cancer therapy-induced cardiomyopathy. Circulation, 140(1), 31-41. https://doi.org/10.1161/ CIRCULATIONAHA.118.037934.

144. Beer, L. A., Kossenkov, A. V., Liu, Q., et al. (2016). Baseline immunoglobulin E levels as a marker of doxorubicin- and trastuzumab-associated cardiac dysfunction. Circulation Research, 119(10), 1135-1144. https://doi.org/10.1161/ CIRCRESAHA.116.309004.

145. Ngo, D., Sinha, S., Shen, D., et al. (2016). Aptamer-based proteomic profiling reveals novel candidate biomarkers and pathways in cardiovascular disease. Circulation, 134(4), 270-285. https:// doi.org/10.1161/CIRCULATIONAHA.116.021803.

146. Lind, L., Ärnlöv, J., Lindahl, B., Siegbahn, A., Sundström, J., \& Ingelsson, E. (2015). Use of a proximity extension assay proteomics chip to discover new biomarkers for human atherosclerosis. Atherosclerosis, 242(1), 205-210. https://doi.org/10.1016/j. atherosclerosis.2015.07.023.

147. Jensen, B. V., Nielsen, S. L., \& Skovsgaard, T. (1996). Treatment with angiotensin-converting-enzyme inhibitor for epirubicin-induced dilated cardiomyopathy. Lancet, 347(8997), 297-299. https://doi.org/10.1016/S0140-6736(96)90469-9.

148. Okumura, K., Jin, D., Takai, S., \& Miyazaki, M. (2002). Beneficial effects of angiotensin-converting enzyme inhibition in adriamycin-induced cardiomyopathy in hamsters. Japanese Journal of Pharmacology, 88(2), 183-188. https://doi.org/10. 1254/jjp.88.183.

149. Cardinale, D., Ciceri, F., Latini, R., et al. (2018). Anthracyclineinduced cardiotoxicity: a multicenter randomised trial comparing two strategies for guiding prevention with enalapril: The International CardioOncology Society-one trial. European Journal of Cancer, 94, 126-137. https://doi.org/10.1016/J.EJCA. 2018.02.005.

150. Gulati, G., Heck, S. L., Røsjø, H., et al. (2017). Neurohormonal blockade and circulating cardiovascular biomarkers during anthracycline therapy in breast cancer patients: results from the PRADA (Prevention of Cardiac Dysfunction During Adjuvant Breast Cancer Therapy) study. Journal of the American Heart Association, 6(11). https://doi.org/10.1161/JAHA.117.006513.

151. Avila, M. S., Ayub-Ferreira, S. M., de Barros Wanderley, M. R., et al. (2018). Carvedilol for prevention of chemotherapy-related cardiotoxicity: The CECCY trial. Journal of the American College of Cardiology, 71(20), 2281-2290. https://doi.org/10. 1016/j.jacc.2018.02.049.

152. ISRCTN24439460. The Cardiac CARE Trial - can heart muscle injury related to chemotherapy be prevented? Http:// W w w. W ho. I n t / T r i a $1 \mathrm{~s}$ e a $\mathrm{r} \mathrm{c} \mathrm{h} /$ Trial2.Aspx?TrialID=ISRCTN24439460. Available at: https:// www.cochranelibrary.com/central/doi/10.1002/central/CN01887176/full. Accessed December 22, 2019.

153. Cardinale, D., \& Cipolla, C. M. (2016). Chemotherapy-induced cardiotoxicity: importance of early detection. Expert Review of Cardiovascular Therapy, 14(12), 1297-1299. https://doi.org/10. 1080/14779072.2016.1239528.

154. Cardinale, D., \& Sandri, M. T. (2015). Detection and monitoring of cardiotoxicity by using biomarkers: pros and cons: remarks on the international colloquium on cardioncology. Progress in Pediatric Cardiology, 39(2), 77-84. https://doi.org/10.1016/J. PPEDCARD.2015.10.004.

155. Tocchetti, C. G., Molinaro, M., Angelone, T., et al. (2015). Nitroso-redox balance and modulation of basal myocardial function: an update from the Italian Society of Cardiovascular Research (SIRC). Current Drug Targets, 16(8), 895-903.

156. Zuppinger, C., \& Suter, T. M. (2010). Cancer therapy-associated cardiotoxicity and signaling in the myocardium. Journal of Cardiovascular Pharmacology, 56(2), 141-146. https://doi.org/ 10.1097/FJC.0b013e3181e0f89a.

Publisher's Note Springer Nature remains neutral with regard to jurisdictional claims in published maps and institutional affiliations. 